\title{
Hot Deformation Behavior of As-Cast 2101 Grade Lean Duplex Stainless Steel and the Associated Changes in Microstructure and Crystallographic Texture
}

\author{
SUDIPTA PATRA, ABHIJIT GHOSH, LOKESH KUMAR SINGHAL, \\ ARIJIT SAHA PODDER, JAGMOHAN SOOD, VINOD KUMAR, \\ and DEBALAY CHAKRABARTI
}

\begin{abstract}
The hot deformation behavior of 2101 grade lean duplex stainless steel (DSS, containing $\sim 5 \mathrm{wt}$ pet $\mathrm{Mn}, \sim 0.2$ wt pet $\mathrm{N}$, and $\sim 1.4$ wt pet $\mathrm{Ni}$ ) and associated microstructural changes within $\delta$-ferrite and austenite $(\gamma)$ phases were investigated by hot-compression testing in a GLEEBLE 3500 simulator over a range of deformation temperatures, $T_{\text {def }}\left[1073 \mathrm{~K}\right.$ to $1373 \mathrm{~K}\left(800{ }^{\circ} \mathrm{C}\right.$ to $\left.1100{ }^{\circ} \mathrm{C}\right)$ ], and applied strains, $\varepsilon(0.25$ to 0.80$)$, at a constant true strain rate of $1 / \mathrm{s}$. The microstructural softening inside $\gamma$ was dictated by discontinuous dynamic recrystallization (DDRX) at a higher $T_{\text {def }}\left[1273 \mathrm{~K}\right.$ to $1373 \mathrm{~K}\left(1000{ }^{\circ} \mathrm{C}\right.$ to $\left.\left.1100{ }^{\circ} \mathrm{C}\right)\right]$, while the same was dictated by continuous dynamic recrystallization $(\mathrm{CDRX})$ at a lower $T_{\text {def }}\left(1173 \mathrm{~K}\left(900{ }^{\circ} \mathrm{C}\right)\right]$. Dynamic recovery (DRV) and CDRX dominated the softening inside $\delta$-ferrite at $T_{\text {def }} \geq 1173 \mathrm{~K}\left(900{ }^{\circ} \mathrm{C}\right)$. The dynamic recrystallization (DRX) inside $\delta$ and $\gamma$ could not take place upon deformation at $1073 \mathrm{~K}\left(800{ }^{\circ} \mathrm{C}\right)$. The average flow stress level increased 2 to 3 times as the $T_{\text {def }}$ dropped from 1273 to $1173 \mathrm{~K}\left(1000{ }^{\circ} \mathrm{C}\right.$ to $\left.900{ }^{\circ} \mathrm{C}\right)$ and finally to $1073 \mathrm{~K}\left(800{ }^{\circ} \mathrm{C}\right)$. The average microhardness values taken from $\delta$-ferrite and $\gamma$ regions of the deformed samples showed a different trend. At $T_{\text {def }}$ of $1373 \mathrm{~K}\left(1100{ }^{\circ} \mathrm{C}\right)$, microhardness decreased with the increase in strain, while at $T_{\text {def }}$ of $1173 \mathrm{~K}\left(900{ }^{\circ} \mathrm{C}\right)$, microhardness increased with the increase in strain. The microstructural changes and hardness variation within individual phases of hot-deformed samples are explained in view of the chemical composition of the steel and deformation parameters $\left(T_{\mathrm{def}}\right.$ and $\left.\varepsilon\right)$.
\end{abstract}

DOI: $10.1007 / \mathrm{s} 11661-016-3759-1$

(C) The Minerals, Metals \& Materials Society and ASM International 2016

\section{INTRODUCTION}

DUPLEX stainless steel (DSS) containing austenite $(\gamma)$ and ferrite $(\delta)$ in equal proportion is widely used in oil, gas, paper, desalination, and petrochemical industries as the economical alternative to austenitic stainless steel. ${ }^{[1]}$ DSS shows high mechanical strength along with excellent resistance to corrosion and stress-corrosion cracking. Since the processing of DSS involves high-temperature deformation, such as hot rolling and hot forging, it is important to study the hot deformation behavior of this steel. $^{[2-12]}$ The changes in microstructure and crystallographic texture during hot deformation of DSS determine

SUDIPTA PATRA, Doctoral Student, is with the Indian Institute of Technology Kharagpur, Kharagpur, West Bengal 721302, India, and also with Jindal Stainless Limited, Hisar, Haryana 125005, India. Contact email: psudiptapatra@gmail.com ABHIJIT GHOSH, formerly Doctoral Student with the Indian Institute of Technology Kharagpur, is now Research Associate with the Indian Institute of Science, Bangalore, India. LOKESH KUMAR SINGHAL, Head, R\&D, ARIJIT SAHA PODDER, GM, R\&D, and JAGMOHAN SOOD, Head, Operation, are with Jindal Stainless Limited. VINOD KUMAR, DGM, is with the R\&D Center for Iron and Steel, RDCIS, SAIL, Ranchi, Jharkhand 834002, India. DEBALAY CHAKRABARTI, Associate Professor, is with the Indian Institute of Technology Kharagpur.

Manuscript submitted March 31, 2016.

Article published online November 4, 2016
(1) the resistance against deformation, i.e., load required for deformation; (2) the resistance to hot cracking during deformation; and (3) the final microstructure and mechanical properties of the steel. Now the hot-flow behavior of DSS depends on microstructural and textural changes taking place within individual phases and their mutual correspondence. Several studies have been carried out on the microstructural evolution during hot deformation of conventional (high-Ni) DSS. ${ }^{[2-11,13-17]}$ The samples of DSS were deformed over a wide temperature range $\left[T_{\text {def }}=\right.$ $1123 \mathrm{~K}$ to $1473 \mathrm{~K}\left(750{ }^{\circ} \mathrm{C}\right.$ to $\left.1200{ }^{\circ} \mathrm{C}\right)$ ] and strain-rate range $(\dot{\varepsilon}=0.01$ to $10 / \mathrm{s})$ using different techniques, such as hot-compression tests, hot-torsion tests, plane-strain compression tests, and laboratory scale hot forging and hot rolling. The general observations are as follows.

(1) Decrease in $T_{\text {def }}$ and increase in $\dot{\varepsilon}$, i.e., the increase in the Zener-Holloman parameter, $Z$, increases the flow stress.

(2) Higher $T_{\text {def }}\left[>1273 \mathrm{~K}\left(1000^{\circ} \mathrm{C}\right)\right]$ and lower $\dot{\varepsilon}(<1 /$ s) provide better hot workability to the steel.

(3) Deformation at low- $Z$ condition can lead to dynamic flow softening, as indicated by the steady-state flow behavior or sharp peak in the flow curve.

(4) Due to its high stacking fault energy, $\delta$-ferrite is prone to flow soften by dynamic recovery (DRV). 
Heavy deformation leads to continuous dynamic recrystallization (CDRX) of ferrite aided by pronounced DRV.

(5) Due to comparatively low stacking fault energy, austenite is less prone to recovery and undergoes conventional (discontinuous) dynamic recrystallization.

Processing at very high temperature and low strain rate is not industrially favorable, as it can hamper the energy efficiency and productivity of the mill. In order to carry out high-temperature deformation, the requirement of high soaking temperature can also be associated to energetic and environmental concerns.

Lean DSS grades, such as 2101 grade steel having 1.0 to $1.5 \mathrm{wt}$ pet $\mathrm{Ni}$ and no Mo addition, have emerged as the most economical version of DSS and are increasingly becoming popular for industrial and household applications. ${ }^{[18-20]}$ Compared to the studies on conventional high-Ni DSS, very limited studies exist on the hot deformation and dynamic restoration behavior of lean DSS. Liu et al. ${ }^{[19]}$ performed single-pass and multipass deformation on as-forged 2101 grade DSS at $T_{\mathrm{def}}$ in the range of $1273 \mathrm{~K}$ to $1373 \mathrm{~K}\left(1000{ }^{\circ} \mathrm{C}\right.$ to $\left.1100{ }^{\circ} \mathrm{C}\right)$ and observed DRV and CDRX inside both $\delta$-ferrite and $\gamma$ at high applied strain. Zou et al. ${ }^{[20]}$ studied the response of as-cast 23 wt pct $\mathrm{Cr}$ lean DSS upon hot-compression testing at $T_{\text {def }}$ in the range of $1273 \mathrm{~K}$ to $1323 \mathrm{~K}\left(1000{ }^{\circ} \mathrm{C}\right.$ to $1050{ }^{\circ} \mathrm{C}$ ) and reported the occurrence of DRV inside both $\delta$-ferrite and $\gamma$. In a recent article, the present authors ${ }^{[21]}$ reported the strain-induced precipitation of secondary austenite islands inside the $\delta$-ferrite matrix during hot deformation of lean DSS. Precipitation of the austenite islands was found to increase with the decrease in deformation temperature from $1373 \mathrm{~K}$ to $1173 \mathrm{~K}\left(1100{ }^{\circ} \mathrm{C}\right.$ to $\left.900{ }^{\circ} \mathrm{C}\right)$ and with the increase in applied strain from 0.3 to 0.8 . The precipitated austenite islands were found to maintain mostly a Kurdjumov-Sachs (K-S) orientation relationship with the $\delta$-ferrite matrix. As the K-S interphase boundaries are prone to hot cracking, precipitation of the secondary austenite affects the hot workability of DSS. Therefore, the hot-flow behavior and microstructural softening taking place within lean DSS may not necessarily follow the aforementioned general trend shown by high-Ni DSS. Earlier studies on the hot deformation of lean DSS hardly looked at the evolution of crystallographic texture within this alloy. According to a recent study from Ghosh et al., ${ }^{[22]}$ crystallographic texture can also influence the mechanical properties such as the impact toughness of steel, as local texture banding can cause fissure formation during Charpy impact testing. Hence, in view of the industrial processing of DSS, as well as for scientific understanding, further studies on the microstructural and textural evolution during hot deformation of lean DSS are necessary. The study on hot deformation of lean DSS becomes even more important as such steel is prone to hot cracking. ${ }^{[1,18-20]}$ Since, during industrial processing, hot-rolling or hot-forging treatments are generally carried out on as-cast and reheated steel, it is preferable to carry out high-temperature deformation simulation on as-cast starting material. Therefore, the main aim of the present study is to identify the softening mechanisms taking place by following the microstructural and textural evolution within the constituent phases ( $\delta$-ferrite and austenite) of as-cast lean DSS during hot deformation, as a function of applied strain and deformation temperature.

\section{EXPERIMENTAL DETAILS}

An industrial 2101 grade DSS was used for the present study. The material was received in the form of as continuously cast slab ( $200-\mathrm{mm}$ thick) from Jindal Stainless Limited (Hisar). The chemical composition of the investigated steel is given in Table I.

Cylindrical samples (10-mm diameter and $15-\mathrm{mm}$ height) were prepared from the quarter-thickness location of the as-cast slab and were hot-compression tested in GLEEBLE 3500* thermomechanical simulator. The NY

*GLEEBLE is a trademark of Dynamic Systems Inc., New York,

thermomechanical processing schedule applied in the present study is shown in Figure 1. A couple of thermocouples spot welded to the samples continuously monitored and controlled the sample temperature at an accuracy of $\pm 3 \mathrm{~K}$. The samples were soaked at $5 \mathrm{~K} / \mathrm{s}$ to different deformation temperatures, $T_{\text {def }}: 1073 \mathrm{~K}(800$ $\left.{ }^{\circ} \mathrm{C}\right), 1173 \mathrm{~K}\left(900{ }^{\circ} \mathrm{C}\right), 1273 \mathrm{~K}\left(1000{ }^{\circ} \mathrm{C}\right)$, and $1373 \mathrm{~K}$ $\left(1100{ }^{\circ} \mathrm{C}\right)$. The samples were compressed up to true strain, $\varepsilon=0.8$, at a strain rate, $\dot{\varepsilon}=1 / \mathrm{s}$, and finally water quenched immediately after deformation. One sample was water quenched directly from the reheating temperature for studying the microstructure generated after reheating treatment. Hot-compression samples were deformed either at $1373 \mathrm{~K}\left(1100{ }^{\circ} \mathrm{C}\right)$ or at $1173 \mathrm{~K}$ $\left(900{ }^{\circ} \mathrm{C}\right)$, to lower strain levels of $\varepsilon=0.25$ or 0.50 . Depending on the $T_{\text {def }}$ and applied strain, $\varepsilon$, the samples were coded as " $T_{\text {def }}-\varepsilon$," such as $1373-0.8,1073-0.8$, 1373-0.5, and 1073-0.5.

The cross section of the compression-tested samples, at the vicinity where thermocouples were attached to the samples (near the center of the samples), was prepared for microstructural and textural study. The electron backscatter diffraction (EBSD) technique was extensively used for phase identification and to investigate the changes in microstructure and texture within each phase, as a result of hot deformation. EBSD scans were performed on the RD-ND plane, where RD stands for the direction of metal flow and ND stands for the direction of compression.

The samples for EBSD analysis were prepared by electropolishing with 90 pct methanol and 10 pct perchloric acid solution. The EBSD study was performed using a HKL Channel 5 system (Oxford Instruments, Oxfordshire, United Kingdom) attached with a Zeiss** Auriga scanning electron microscope at

**Zeiss is a trademark of Carl Zeiss microscopy GmbH, Germany. 
Table I. Chemical Composition (Weight Percent) of the Investigated Steel

\begin{tabular}{lccccccccc}
\hline $\mathrm{C}$ & $\mathrm{Mn}$ & $\mathrm{Cr}$ & $\mathrm{Si}$ & $\mathrm{N}$ & $\mathrm{P}$ & $\mathrm{S}$ & $\mathrm{Ni}$ & $\mathrm{Mo}$ & $\mathrm{Cu}$ \\
\hline 0.025 & 5.1 & 21.37 & 0.44 & 0.209 & 0.032 & 0.002 & 1.44 & 0.2 & 0.15 \\
\hline
\end{tabular}

Table II. Microstructural Characterization of the Deformed Samples by EBSD

\begin{tabular}{|c|c|c|c|c|c|c|c|}
\hline \multirow[b]{2}{*}{$\begin{array}{l}\text { Sample } \\
\text { Code }\end{array}$} & \multicolumn{3}{|c|}{$\delta$-Ferrite } & \multicolumn{4}{|c|}{ Austenite $(\gamma)$} \\
\hline & $\begin{array}{c}\text { Rex. } \\
\text { Fraction } \\
\text { in } \delta(\mathrm{Pct}) \\
\end{array}$ & $\begin{array}{c}\text { Average } \\
\text { Rex. } \Delta \\
\text { Grain } \\
\text { Size }(\mu \mathrm{m}) \\
\end{array}$ & $\begin{array}{l}\text { Estimated } \\
\text { Fraction } \\
\text { of HABs (Pct) }\end{array}$ & $\begin{array}{c}\text { Rex. } \\
\text { Fraction } \\
\text { in } \gamma(\text { Pct })\end{array}$ & $\begin{array}{l}\text { Avg. } \\
\text { Rex. } \gamma \text { Grain } \\
\text { Size }(\mu \mathrm{m})\end{array}$ & $\begin{array}{c}\text { Local } \\
\text { Average } \\
\text { Misorientation } \\
\text { (Degree) }\end{array}$ & $\begin{array}{c}\text { Estimated } \\
\text { Fraction of } \\
\text { Twin Boundaries } \\
\text { Among All } \\
\text { Boundaries (Pct) }\end{array}$ \\
\hline $1373-0.25$ & $9 \pm 3$ & $4.3 \pm 1$ & 3 & 0 & $3 \pm 1$ & $0.8 \pm 0.3$ & 1.6 \\
\hline $1373-0.50$ & $50 \pm 3$ & $12 \pm 4$ & 14 & $15 \pm 2$ & $8 \pm 3$ & $0.5 \pm 0.4$ & 16 \\
\hline $1373-0.8$ & $75 \pm 3$ & $18 \pm 10$ & 35 & $68 \pm 6$ & $20 \pm 4$ & $0.35 \pm 0.1$ & 28 \\
\hline $1273-0.8$ & $60 \pm 4$ & $17 \pm 5$ & 25 & $31 \pm 4$ & $12 \pm 3$ & $0.45 \pm 0.3$ & 17 \\
\hline $1173-0.25$ & 0 & $1.5 \pm 0.5$ & 4.8 & 0 & - & $0.75 \pm 0.5$ & 0.06 \\
\hline $1173-0.5$ & $6 \pm 2$ & $4.2 \pm 3$ & 11 & $4 \pm 2$ & $2 \pm 0.5$ & $0.9 \pm 0.4$ & 0.10 \\
\hline $1173-0.8$ & $30 \pm 4$ & $5.3 \pm 3$ & 16 & $14 \pm 3$ & $4 \pm 1$ & $0.65 \pm 0.4$ & 10 \\
\hline $1073-0.8$ & $2 \pm 1$ & $1.0 \pm 0.3$ & 2 & 0 & - & $1.5 \pm 0.5$ & 0.6 \\
\hline
\end{tabular}

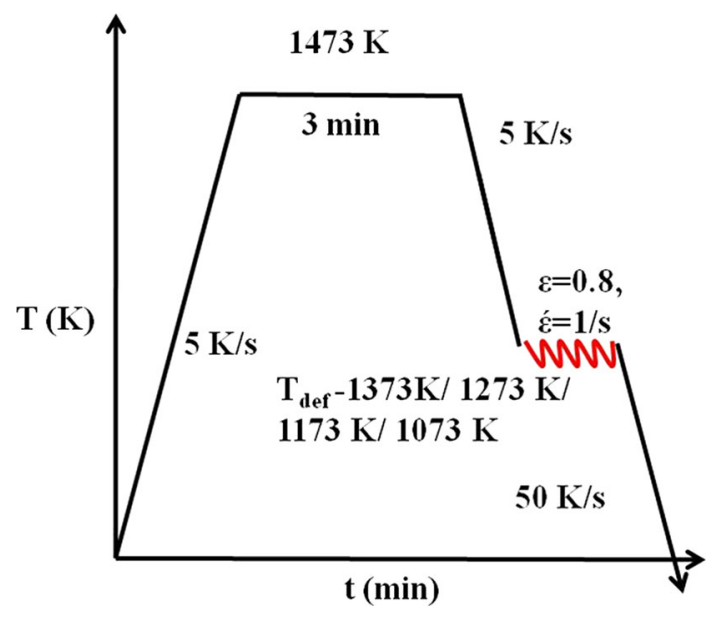

Fig. 1-Schematic diagram of the thermomechanical processing schedule used in the present study.

70-deg tilting condition, for identification of bcc- $\delta$ and fcc- $\gamma$ phases and for study of the strain distribution, boundary misorientation distribution, and crystallographic orientation within each phase. An area of at least $500 \mu \mathrm{m} \times 500 \mu \mathrm{m}$ was scanned for each sample at a step size of $0.3 \mu \mathrm{m}$. An MTex ${ }^{\dagger}$ toolbox was used for the

\footnotetext{
${ }^{\dagger}$ MTex is a free matlab toolbox for analyzing and modeling crystallographic texture available on http://mtex-toolbox.github.io/.
}

EBSD data analysis. The local average misorientation (LAM) maps were obtained by considering the average misorientation between each point (i.e., each pixel) and its five nearest neighboring points for a maximum

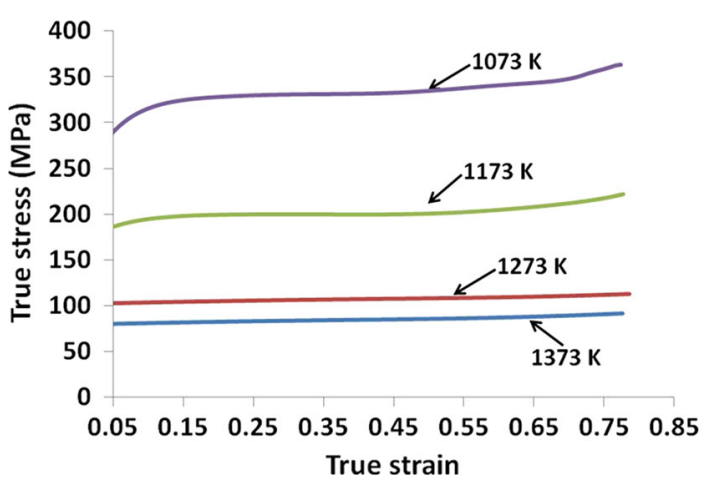

Fig. 2-True stress $v s$ true strain curves of the hot-deformed samples. Deformation temperatures are indicated by arrows.

misorientation of $5 \mathrm{deg}$. LAM maps highlight local strain gradients, independent of grain size. The boundary misorientation distribution was conducted by considering all the boundaries having misorientation greater than 2 deg. Following general convention, high-angle "grain boundaries" (indicated by thick black lines) and low-angle "sub-boundaries" (indicated by thin black lines) are defined as the boundaries having misorientations greater than $15 \mathrm{deg}$ and between 2 and $15 \mathrm{deg}$, respectively. Since two different phases $(\delta$ and $\gamma)$ are present in DSS having different crystal structures, it is necessary to study the changes in texture as a result of hot deformation, within each phase. Microtexture study using EBSD is preferred from this respect rather than macrotexture study, which presents the combined texture of both $\delta$ and $\gamma$, over a larger microstructural area. Thin foils were prepared by electropolishing in $10 \mathrm{pct}$ perchloric acid in acetic acid solution, and the foils were 

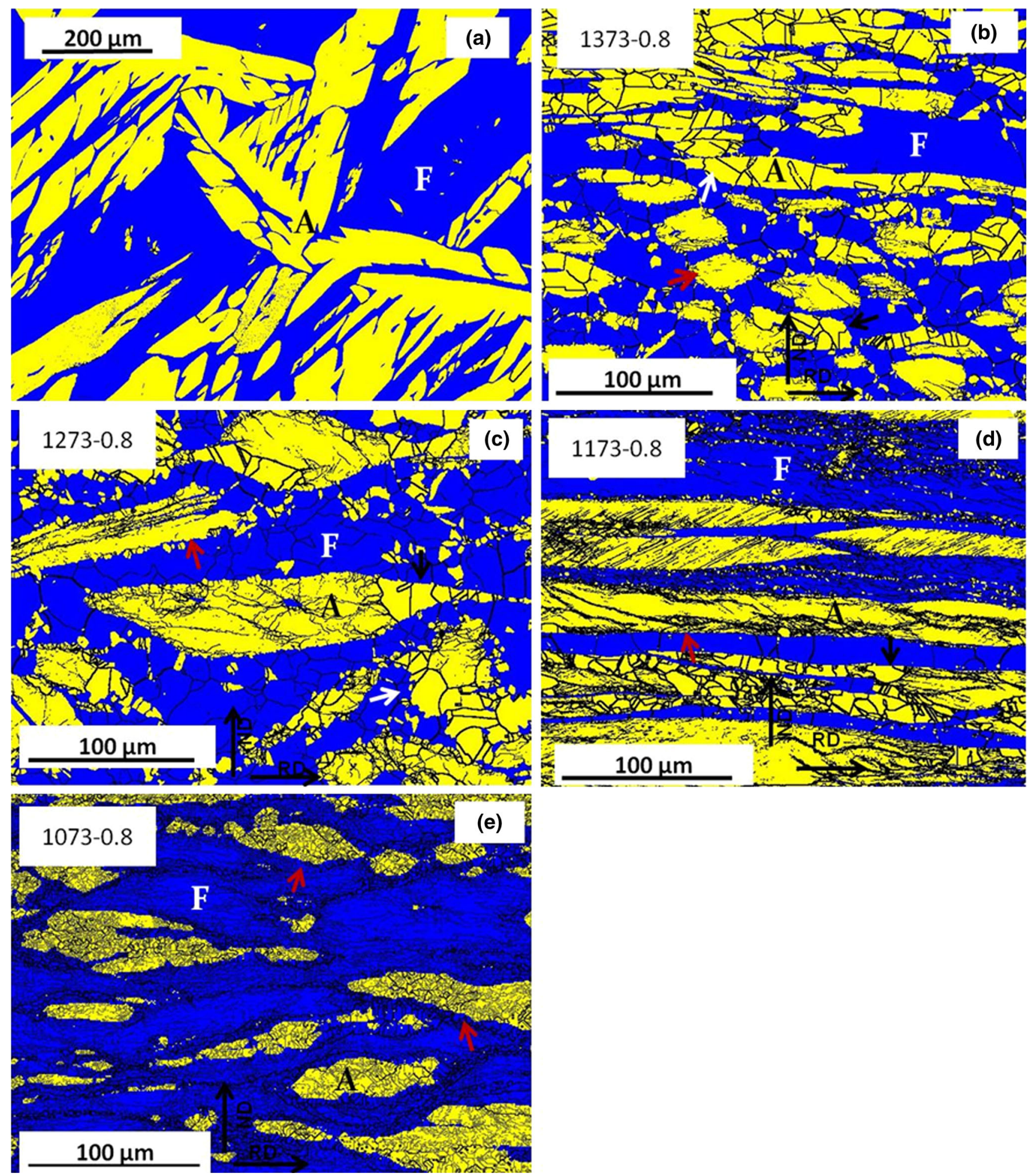

Fig. 3-EBSD phase map of the $(a)$ as-cast and reheated and $(b)$ through $(e)$ hot-compression-tested samples for different deformation temperatures, as mentioned on the images, and at an applied strain of 0.8 . $\delta$-ferrite $(\mathrm{F})$ and austenite (A) regions are shown in "blue" and "yellow," respectively. ND stands for the compression direction, and RD shows the direction of metal flow (Color figure online). 

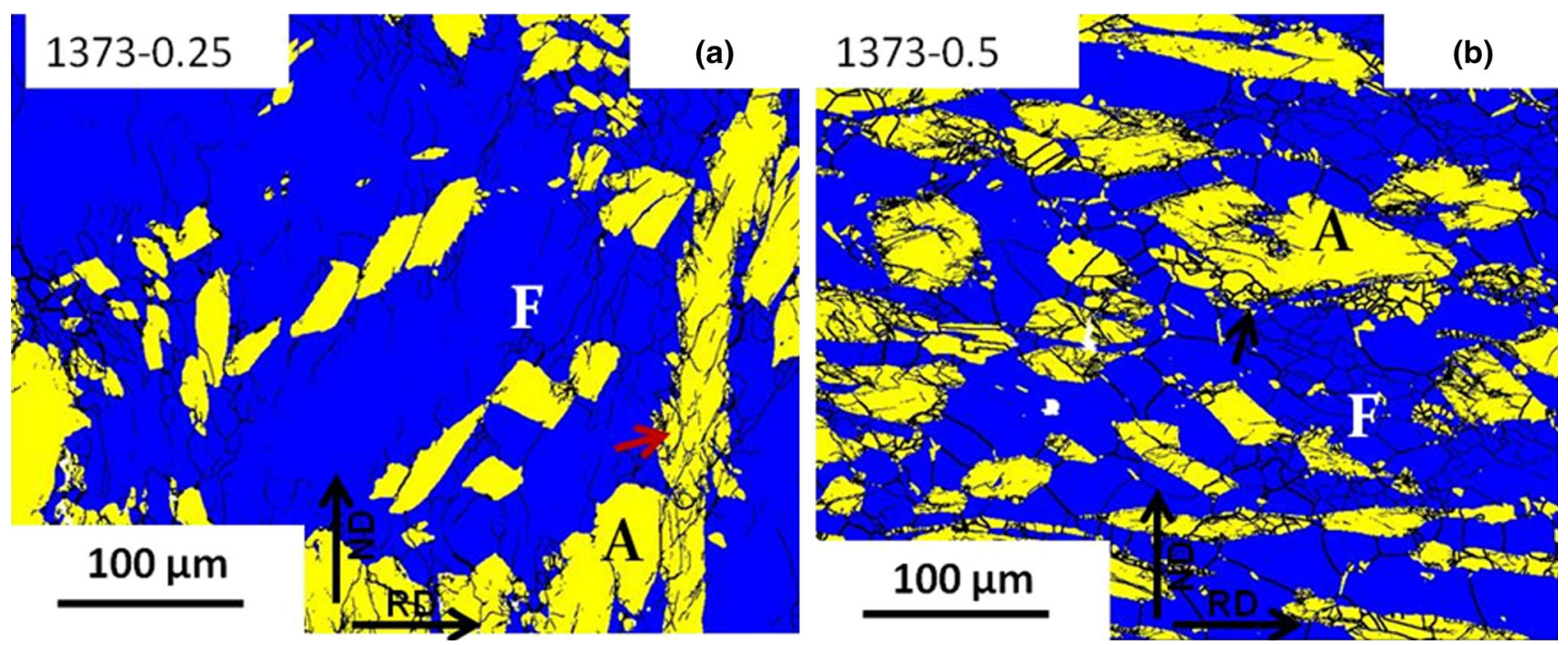

Fig. 4-EBSD phase map of the samples tested at $1373 \mathrm{~K}\left(1100{ }^{\circ} \mathrm{C}\right)$ up to two different strain levels: $(a) \varepsilon=0.25$ and $(b) \varepsilon=0.50$. Austenite (A) and ferrite (F) regions are in "yellow" and "blue," respectively (Color figure online).

examined using a JEOL ${ }^{\ddagger}$ ZEM-2100 transmission elec-

${ }^{\ddagger} \mathrm{JEOL}$ is a trademark of Japan Electron Optics Ltd., Tokyo.

tron microscope (TEM).

Microhardness measurements were taken separately from $\delta$ and $\gamma$ regions of hot-compression-tested samples as the average of 20 readings, using a WALTER ${ }^{\S} \mathrm{UHL}$

${ }^{\S}$ WALTER UHL is a trademark of technische mikroskopie GMbH \& CO. KG, Germany.

Mikroskopic GmbH at 20 gf (gram-force) load.

\section{RESULTS AND DISCUSSION}

\section{A. Effect of Deformation Temperature on Hot-Flow Behavior}

The true stress $v s$ true strain curves, i.e., flow curves, of the compression-tested samples, for different deformation temperatures, are presented in Figure 2. The serration in the data was removed and the curves were smoothed by applying a high-order polynomial fit, following the established procedure. ${ }^{[23]}$ The flow curves of the samples deformed at $1273 \mathrm{~K}$ and $1373 \mathrm{~K}\left(1000{ }^{\circ} \mathrm{C}\right.$ and $1100{ }^{\circ} \mathrm{C}$ ) showed perfectly steady-state behavior, and the flow stress remained at a low level (80 to 110 $\mathrm{MPa}$ ). These results are similar to the behavior observed by other authors. ${ }^{[19,24]}$ As the $T_{\text {def }}$ decreased to $1173 \mathrm{~K}$ $\left(900{ }^{\circ} \mathrm{C}\right)$ and further to $1073 \mathrm{~K}\left(800{ }^{\circ} \mathrm{C}\right)$, the average flow-stress level increased significantly to $\sim 200 \mathrm{MPa}$ [for $\left.T_{\text {def }}=1173 \mathrm{~K}\left(900{ }^{\circ} \mathrm{C}\right)\right]$ and $\sim 330 \mathrm{MPa}\left[\right.$ for $T_{\text {def }}=1073$ $\left.\mathrm{K}\left(800^{\circ} \mathrm{C}\right)\right]$. The flow curves obtained upon deformation at $1173 \mathrm{~K}$ and $1073 \mathrm{~K}\left(900{ }^{\circ} \mathrm{C}\right.$ and $\left.800^{\circ} \mathrm{C}\right)$ show similar behavior, where the stress increases initially to steady-state level and again toward the end of deformation at $\varepsilon>0.65$. This behavior has not been reported in earlier studies on $\operatorname{DSS}^{[20,24]}$ and can be justified by the following points. First, earlier studies hardly deformed the as-cast samples of lean DSS below $\sim 1273 \mathrm{~K}(1000$ $\left.{ }^{\circ} \mathrm{C}\right)$. Besides that, the increase in flow stress at higher strain levels could be attributed to the strain-induced precipitation of secondary austenite islands at lower deformation temperatures, as reported recently in another study. ${ }^{[21]}$ The fine austenite islands can significantly hinder the plastic flow inside $\delta$-ferrite, resulting in the increase in flow stress. At lower deformation temperatures [1173 $\mathrm{K}$ and $1073 \mathrm{~K}\left(900{ }^{\circ} \mathrm{C}\right.$ and $\left.800{ }^{\circ} \mathrm{C}\right)$ ] and higher strain levels, recovery and recrystallization can be severely restricted in the lean DSS, ${ }^{[13-17]}$ which can significantly increase the flow stress.

The EBSD phase map of reheated and hot-compression-tested samples was presented in Figure 3. Randomly distributed large and elongated $\gamma$ islands were observed in the as-reheated sample (Figure 3(a)). The austenite area fraction was $\sim 45$ pct, which hardly changed after hot deformation (Figure 3). Heavy deformation at $1373 \mathrm{~K}\left(1100{ }^{\circ} \mathrm{C}\right)$ refined the microstructure of the 1373-0.8 sample, and some of the $\gamma$ regions became elongated toward the direction of metal flow (i.e., perpendicular to the compression axis) (Figure 3(b)). Both low-angle boundaries (LABs) and high-angle boundaries (HABs) were present within $\delta$-ferrite phase, as well as within $\gamma$-phase, for this sample (Figure 3(b)). The microstructural characterization of all the hot-deformed samples is presented in Table II. There is a variation in the recrystallized $\delta$-grain size in the hot-deformed samples and the grain size is represented by average grain size and standard deviation, as listed in Table II. The reason behind the high standard deviations in the measured $\delta$-ferrite grain sizes in Table II can be attributed to the heterogeneous distribution of strain in the deformed structure, which resulted in a grain size variation after recrystallization. 


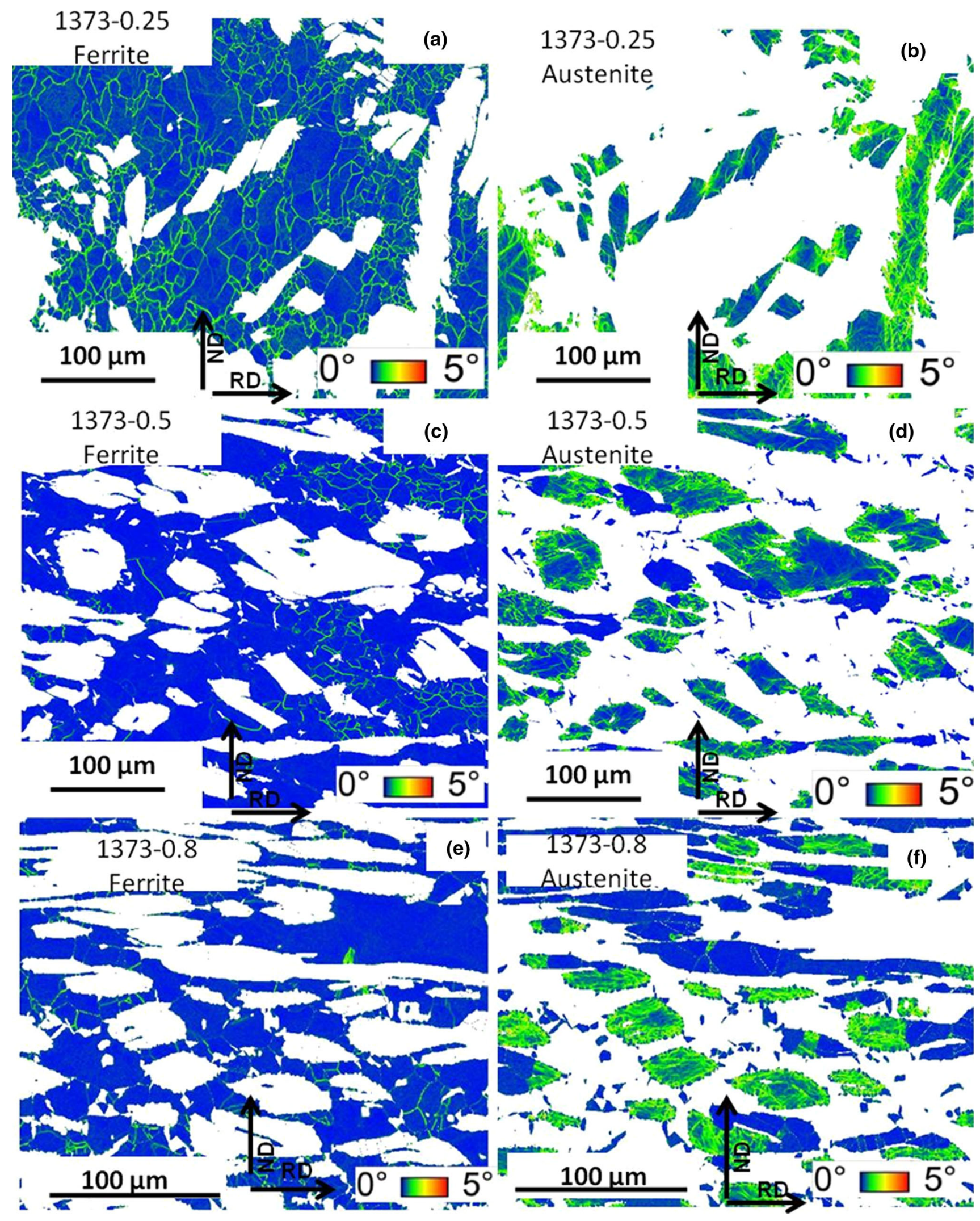

Fig. 5-LAM maps for $(a),(c)$, and $(e)$ ferrite and $(b),(d)$, and $(f)$ austenite region of the samples hot deformed at $1373 \mathrm{~K}\left(1100{ }^{\circ} \mathrm{C}\right)$. The LAM values are represented in the form of color codes as the color legend (for 0 to 5 deg orientation gradient) given on every image (Color figure online). 


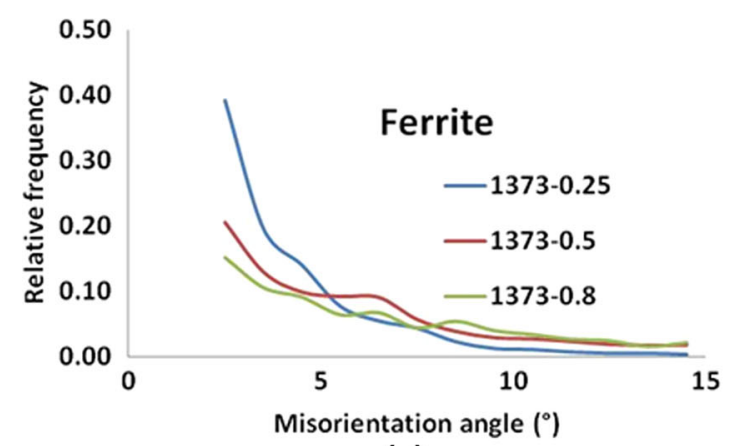

(a)

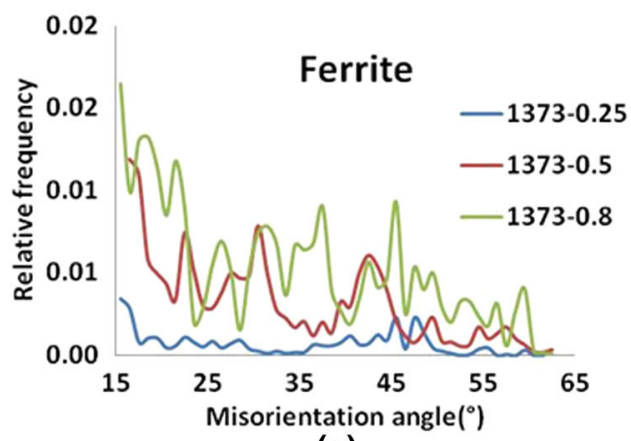

(c)

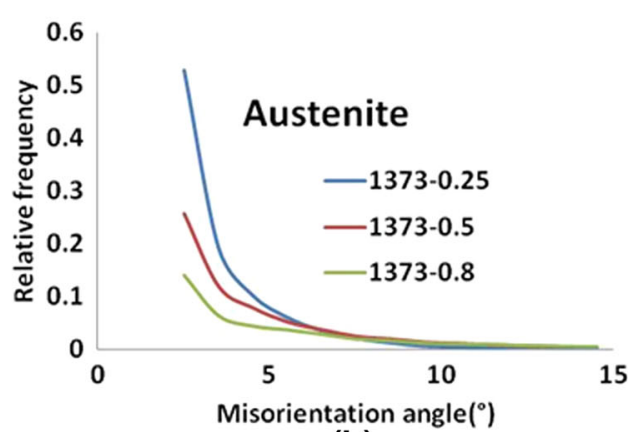

(b)

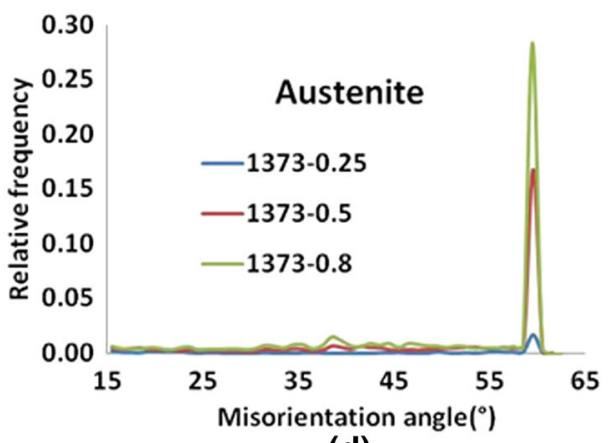

(d)

Fig. 6-Boundary misorientation distributions, as obtained from EBSD analysis, for $(a)$ and $(c) \delta$-ferrite and $(b)$ and $(d)$ austenite regions of the samples deformed at $1373 \mathrm{~K}\left(1100^{\circ} \mathrm{C}\right)$ up to different strain levels.

The $\delta$-ferrite matrix appeared to be relatively strain free. Several twin boundaries formed inside the deformed and elongated $\gamma$-phase regions in the 1373-0.8 sample, as indicated by black arrows in Figure 3(b). The regions containing twins appeared to be the strain-free regions in $\gamma$, as indicated by red arrows in Figure 3(b). The presence of twin bands in strain-free $\gamma$ regions denotes that those twins were possibly the annealing twins that formed as a result of dynamic recrystallization (DRX) inside $\gamma$. The remaining $\gamma$ regions contained LABs, which indicates that dislocation substructures formed inside $\gamma$ upon deformation (by slip) and DRV. The presence of sub-boundaries inside both $\delta$ and $\gamma$ suggests that DRV occurred inside both these phases during deformation.

As the deformation temperature decreased to $1273 \mathrm{~K}$ and $1173 \mathrm{~K}\left(1000{ }^{\circ} \mathrm{C}\right.$ and $\left.900{ }^{\circ} \mathrm{C}\right)$, the proportion of strain-free regions inside $\delta$ and $\gamma$ decreased continuously and extensive dislocation substructures (LABs) formed within those phases (Figures 3(c) and (d) and Table II). Deformation twins can be seen in the deformed $\gamma$ regions of the 1173-0.8 sample, as indicated by red arrows in Figure 3(d). The size of recrystallized $\delta$ and $\gamma$ grains decreased with the decrease in deformation temperature (Table II and Figure 3). Fine strain-free recrystallized grains, less than $10 \mu \mathrm{m}$ in size, were observed at the recrystallized $\gamma$ regions of the 1173-0.8 sample, as indicated by black arrows in Figure 3(d). Upon heavy straining, deformation twins can deviate from ideal twin orientation by slip-twin interaction. Therefore, the deformation in $\gamma$ regions of lean DSS seems to be contributed by both slipping and twinning mechanisms.
Hot compression at $1073 \mathrm{~K} \quad\left(800{ }^{\circ} \mathrm{C}\right)$ severely deformed both the $\delta$ and $\gamma$ phases. Numerous subgrains, surrounded by LABs, were found to form inside the deformed $\gamma$ regions (indicated by red arrows) of the 1073-0.8 sample. The possibility of DRX of both $\delta$ and $\gamma$ can be ruled out in the 1073-0.8 sample, as neither annealing twins nor fine strain-free grains were present (Figure 3(e)). Therefore, the dynamic softening in lean DSS seems to be governed by DRV and DRX both inside $\delta$-ferrite and in $\gamma$. DRV in this case must have played the predominant role, as indicated by the prolonged steady-state hot-flow behavior in the flow curves (Figure 2). In order to understand this aspect in greater detail, samples were deformed at two different temperatures $\left[1373 \mathrm{~K}\left(1100{ }^{\circ} \mathrm{C}\right)\right.$ or $\left.1173 \mathrm{~K}\left(900^{\circ} \mathrm{C}\right)\right]$ at different strain levels $(0.25$ or 0.5$)$ and the effect of strain on microstructural and textural changes was studied.

\section{B. Effect of Applied Strain on Hot-Flow Behavior at $1373 \mathrm{~K}\left(1100^{\circ} \mathrm{C}\right)$ Deformation Temperature}

The EBSD phase maps of the samples deformed up to 0.25 and 0.5 true strain levels at $1373 \mathrm{~K}\left(1100{ }^{\circ} \mathrm{C}\right)$ are shown in Figure 4. The phase map of the sample deformed up to $\varepsilon=0.8$ at the same $T_{\text {def }}$ is already shown in Figure 3(b). In the 1373-0.25 sample, low-angle boundaries, i.e., subgrain boundaries, were present in $\delta$ at the vicinity of $\gamma$ regions, as indicated by red arrows in Figure 4(a). In some cases, those boundaries remained incomplete and were found to evolve from the HABs (Figure 4(a)). As the strain increased to 0.5, the intensity of low-angle subgrain boundaries (indicated by 


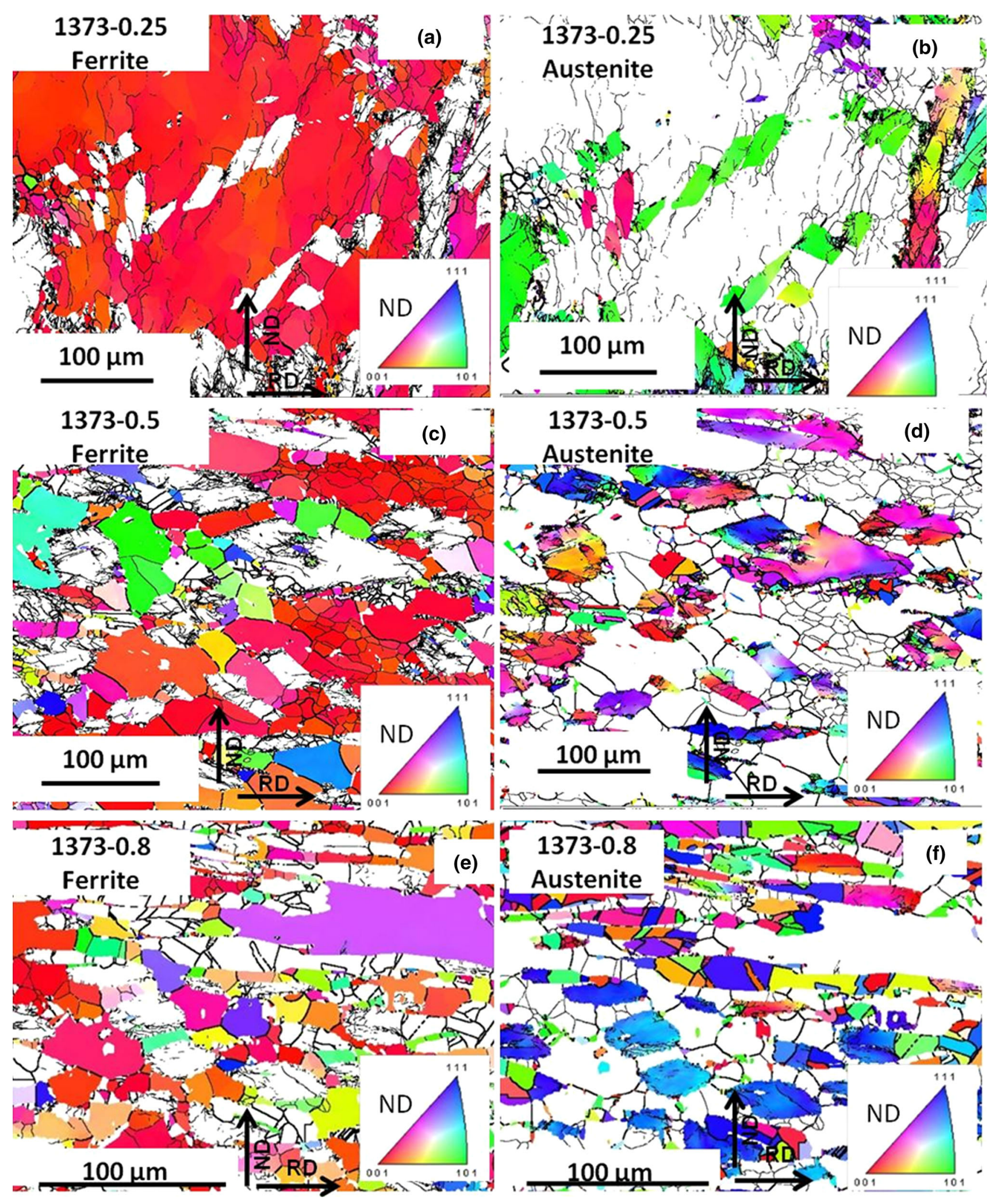

Fig. 7-ND-IPF maps for $(a),(c)$, and $(e) \delta$-ferrite and $(b),(d)$, and $(f)$ austenite regions of the samples deformed at $1373 \mathrm{~K}\left(1100{ }^{\circ} \mathrm{C}\right)$ up to different strain levels. The IPF color legend is given on each image (Color figure online). 
thin black lines) and high-angle grain boundaries (indicated by thick black lines) increased inside the $\delta$ matrix (Figure 4(b)). The subgrain boundaries continued to disappear and were replaced by high-angle grain boundaries with the further increase in applied strain resulting in the formation of fine strain-free grains at an applied strain of 0.8 (Figure 3(b)). This aspect was further confirmed by the TEM analysis presented afterward.

The decrease in the strain level in $\delta$-ferrite matrix and the gradual disappearance of dislocation substructure and LABs become evident from the LAM maps in Figures 5(a), (c), and (e). The LABs appear in the form of a green-colored network in Figures 5(a), (c), and (e), and the blue-colored regions contain low strain gradient (i.e., strain-free matrix). Sub-boundaries gradually disappear and strain-free regions dominate the $\delta$ matrix with the increase in strain. The preceding observation is a clear indication that the microstructural softening in the $\delta$-ferrite matrix is the outcome of pronounced DRV and the resultant CDRX process. In this phenomenon, subgrain boundaries formed due to DRV continue to accumulate dislocations with the increase in strain and gradually convert into high-angle grain boundaries, surrounding strain-free (grain interior) regions. ${ }^{[24,25]}$

Due to the high stacking fault energy along with the high diffusion rate of alloying elements (removing alloy segregation or clustering), dislocation movement is easier in $\delta$-ferrite, which makes it prone to DRV. Due to the presence of $\gamma$, which is less deformable than $\delta$, the deformation starts in $\delta$ and preferentially accumulates strain. As $\delta$ becomes strain hardened, the strain penetrates into $\gamma$. Now, in DSS, due to the presence of $\gamma$, the subgrain boundaries formed inside $\delta$ (sandwiched between the $\gamma$ regions) by the DRV process remain connected to the $\delta / \gamma$ interphase boundaries, which restrict the mobility of sub-boundaries. This promotes the occurrence of $\mathrm{CDRX}$ in $\delta$, especially at the regions close to the $\gamma$ islands, and supports the observation in Figures 3 through 5. The boundary misorientation distribution for $\delta$-ferrite in Figures 6(a) and (c) shows the gradual decrease in the fraction of the LAB, and the corresponding rise in the fraction of the $\mathrm{HAB}$ further confirms the occurrence of CDRX in $\delta$.

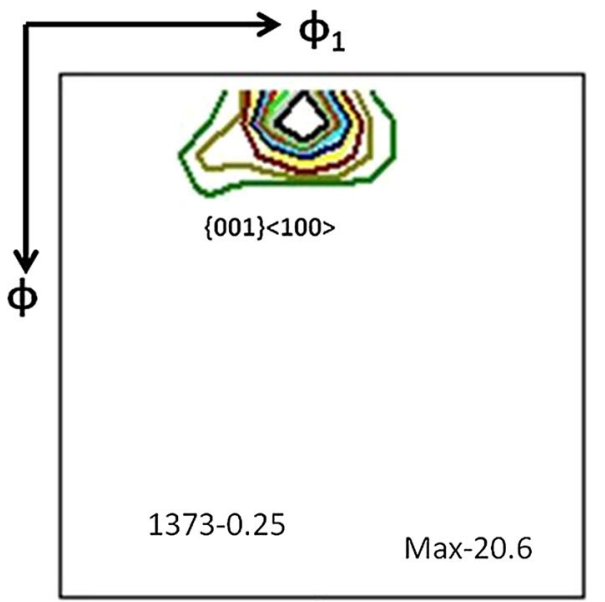

(a)

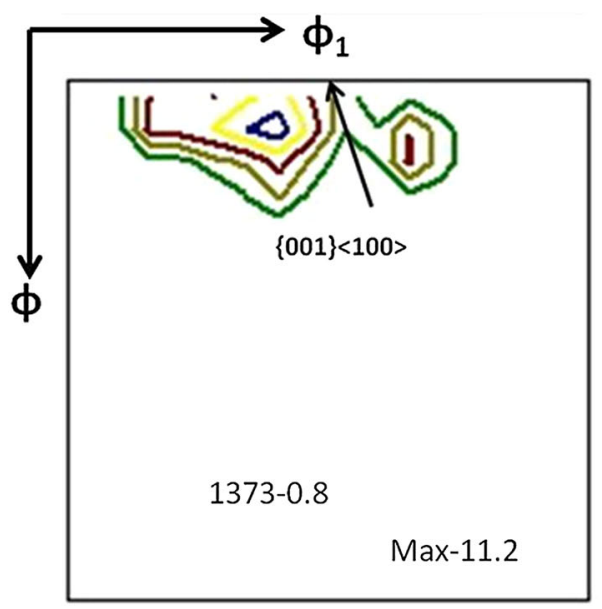

(c)

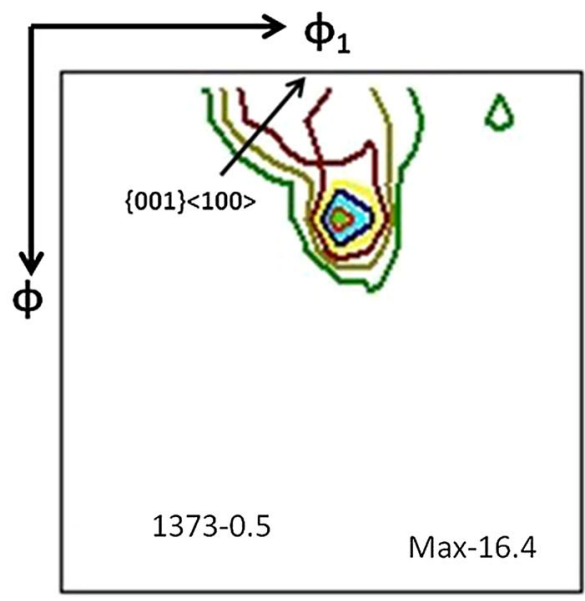

(b)

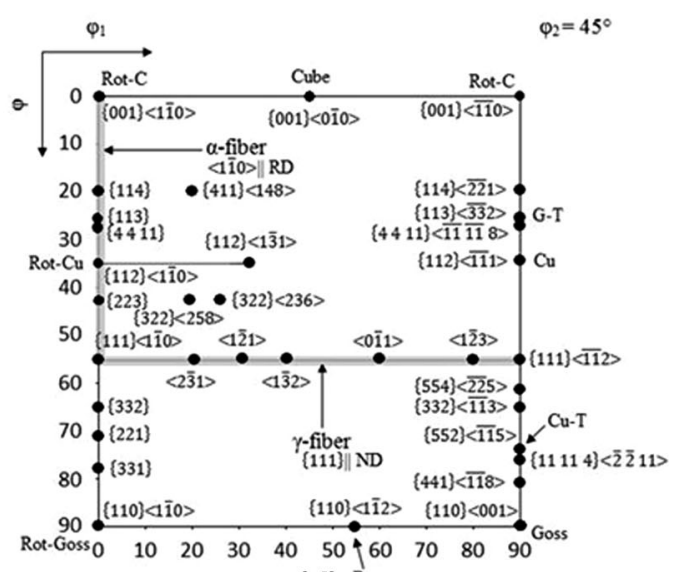

(d) ${ }^{\mathrm{Bs}}$

Fig. 8-ODF presented on the $\Phi_{2}=45$ deg section of Euler space for $\delta$-ferrite regions of hot-deformed samples tested up to different strain levels $\left((a),(b)\right.$, and $(c)$ respectively for $0.25,0.5$, and 0.8 strains) at $1373 \mathrm{~K}\left(1100^{\circ} \mathrm{C}\right)$. (d) Standard ferrite orientations in steel are shown in the $\Phi_{2}$ $=45 \mathrm{deg}$ ODF section. 


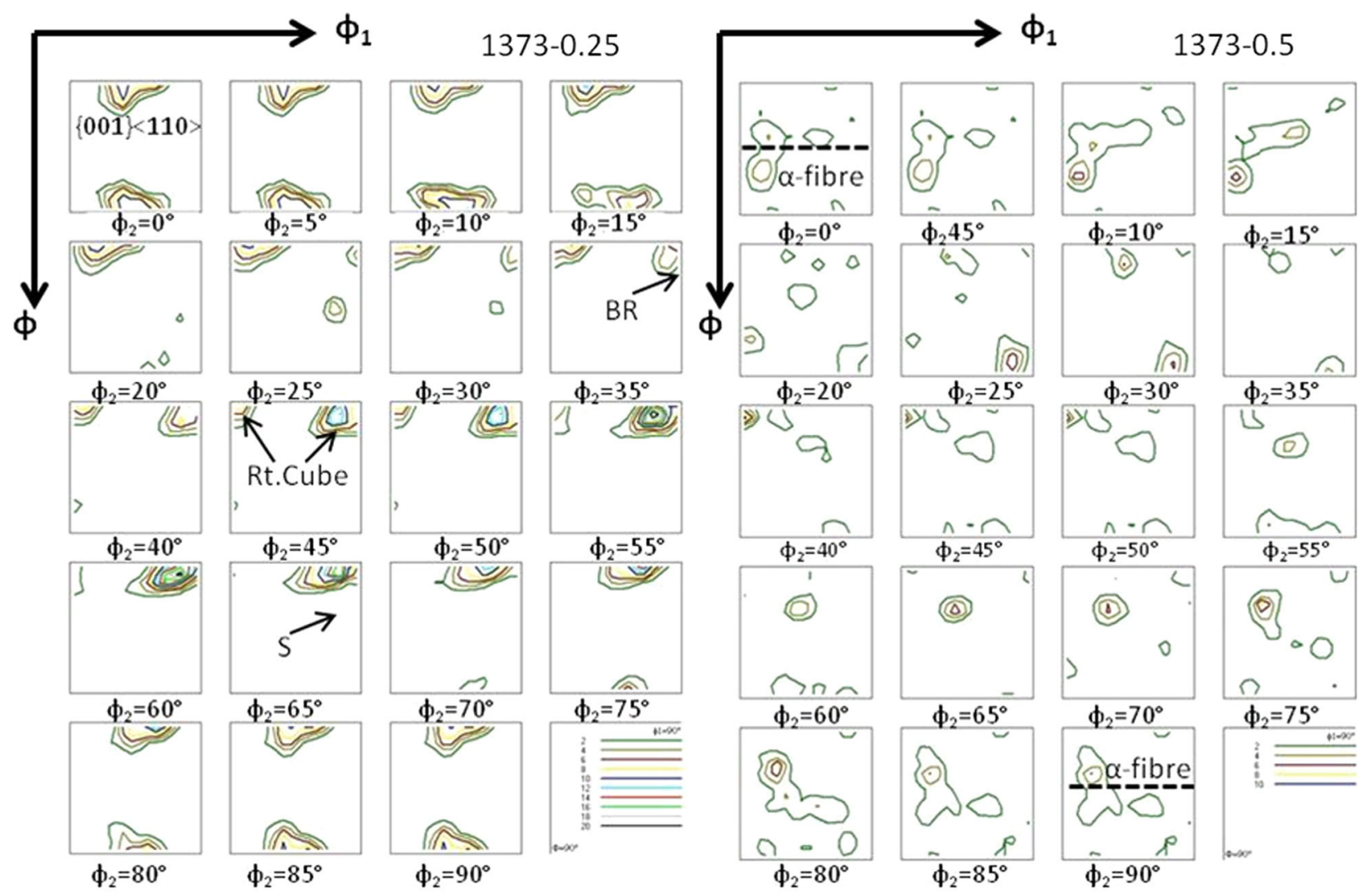

(a)

(b)

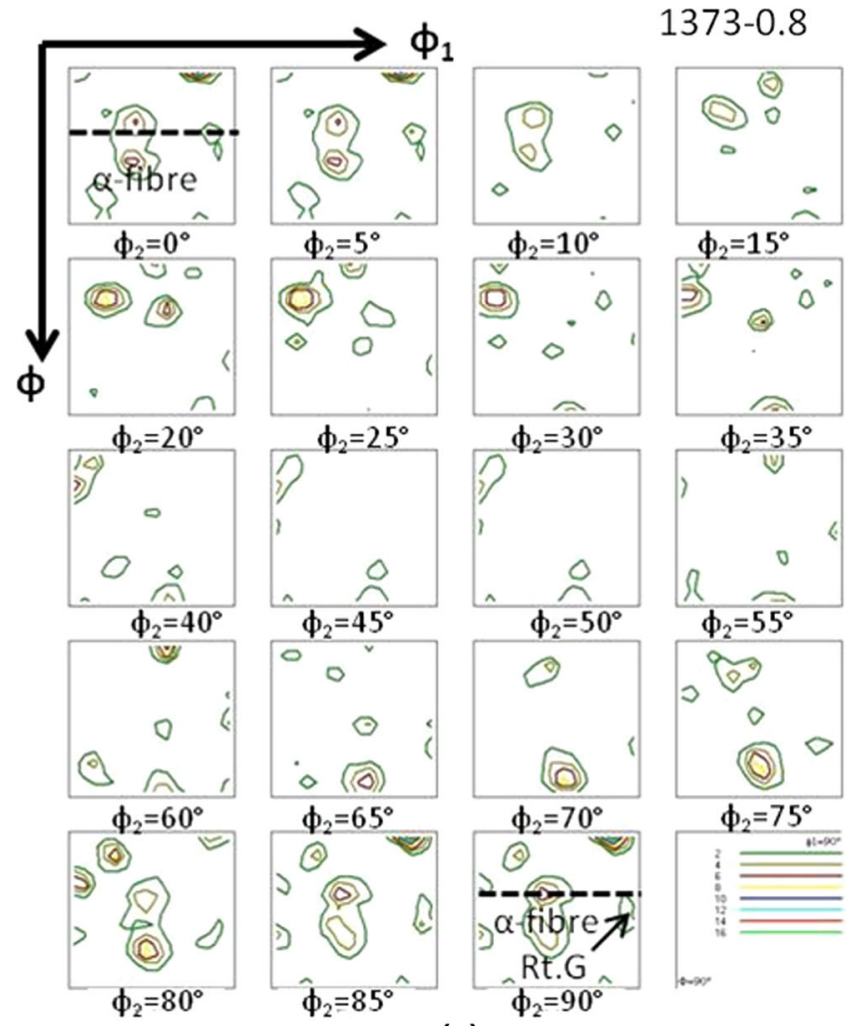

(c)

Fig. 9- ODF sections representing the texture in austenite $(\gamma)$ of the samples tested up to different strain levels $((a),(b)$, and $(c)$ respectively for $0.25,0.5$, and 0.8 strains) at $1373 \mathrm{~K}\left(1100{ }^{\circ} \mathrm{C}\right)$. The dominant texture components are mentioned on the images. Abbreviations: Cu $=\mathrm{Copper}$ texture, $\mathrm{S}=\mathrm{S}$ texture, Cube $=$ Cube texture, etc. 

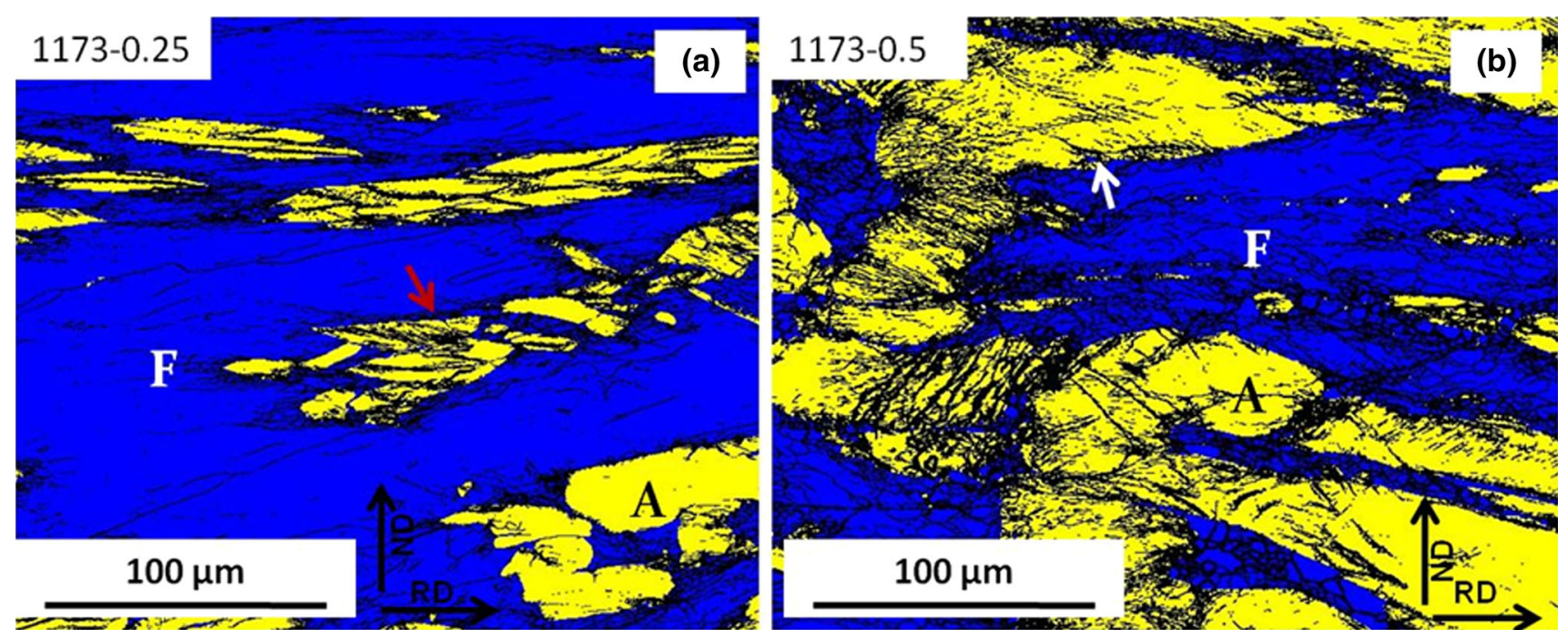

Fig. 10 -EBSD phase map of the samples tested at $1173 \mathrm{~K}\left(900^{\circ} \mathrm{C}\right)$ up to two different strain levels: $(a) \varepsilon=0.25$ and $(b) \varepsilon=0.50$. Austenite (A) and ferrite (F) regions are shown in "yellow" and "blue," respectively (Color figure online).

Austenite $(\gamma)$ regions in the as-reheated sample had different sizes and were oriented in a random fashion. Depending on their size and orientation, with respect to the loading axis, at low applied strain, different $\gamma$ regions were subjected to different amounts of strain (Figure 5(b)). The larger and elongated $\gamma$ regions, oriented along the compression axis, were preferentially deformed (Figure 5(b)), possibly by offering higher resistance to $\delta$-ferrite deformation, as compared to the smaller and more equiaxed $\gamma$ islands. Deformations of $\gamma$ regions reoriented and aligned those regions along the direction of metal flow. As the applied strain increased, heavily deformed and elongated $\gamma$ regions were subjected to discontinuous (i.e., conventional) dynamic recrystallization, which resulted in the formation of annealing twins. At a higher level of deformation $(\varepsilon=0.5$ to 0.8$)$, the strain gradually penetrated inside the smaller $\gamma$ islands, and dislocation arrays and deformation twins formed inside them (Figures 3(b), 4(b), and 5(d) and (f)). The boundary misorientation distribution in Figures 6(b) and (d) shows the gradual decrease in LAB fraction, with the increase in applied strain. The corresponding $\mathrm{HAB}$ fraction increased with strain, where the fraction of $\sum 3$ twin boundaries, having $60-$ deg misorientation with respect to the $\langle 111\rangle$ axis, increased in an abrupt fashion (Figures 6(b) and (d) and Table II). At $T_{\text {def }}=1373 \mathrm{~K}\left(1100^{\circ} \mathrm{C}\right)$, the recrystallized fraction increased with strain in both $\delta$ and $\gamma$ (Table II). The average recrystallized grain size also showed an increase with strain, which can be difficult to explain (Table II). Possibly due to the high deformation temperature, grain growth took place to some extent during or immediately after deformation, before the water quenching. The higher the applied strain, the higher the recrystallized fraction and the frequency of HABs. It may be easier for the HABs to move inside the strain-free (recrystallized) matrix than the strained region. As a result, higher grain growth occurred in the heavily deformed sample, which also had a longer deformation period (for constant strain rate). The average LAM value in $\gamma$ initially decreased upon the increase in strain from 0.25 to 0.50 (Table II), as higher strain penetrated into the $\gamma$ regions. A further increase in strain to 0.8 resulted in DDRX of $\gamma$, and the average LAM decreased (Table II).

\section{Effect of Applied Strain on Crystallographic Texture at $1373 \mathrm{~K}\left(1100^{\circ} \mathrm{C}\right)$ Deformation Temperature}

The inverse pole figure (ND-IPF) maps for ferrite and austenite regions of the samples, deformed at $1373 \mathrm{~K}$ $\left(1100{ }^{\circ} \mathrm{C}\right)$ at different strain levels, are presented in Figure 7. The microtexture of ferrite and austenite regions is presented in the form of an orientation distribution function (ODF) in Figures 8 and 9, respectively. Red-colored ferrite regions in Figures 7(a), (c), and (e) show the dominance of cube and "rotated-cube" textures. The $\Phi_{2}=45 \mathrm{deg}$ ODF sections in Figure 8 also indicate that the cube texture components $(\langle 001\rangle|| N D)$ were present at high intensity inside $\delta$-ferrite, irrespective of the strain level. The standard orientations given in the $\Phi_{2}=45 \mathrm{deg}$ ODF section in Figure 8(d) can be used as the reference to interpret the texture of ferrite. In as-cast DSS, the cube texture $(\langle 001\rangle \| N D)$ is the solidification texture expected to be present in $\delta .{ }^{[19,20]}$ Upon deformation of $\delta$-ferrite, cube texture can deviate from its ideal orientation to form a rotated-cube component. In general, cube and rotatedcube components are very stable (due to their low stored energy) and primarily undergo DRV rather than DDRX. ${ }^{[10,11,26-28]}$

Pronounced DRV leads to CDRX, which does not involve the nucleation and growth of newly oriented 


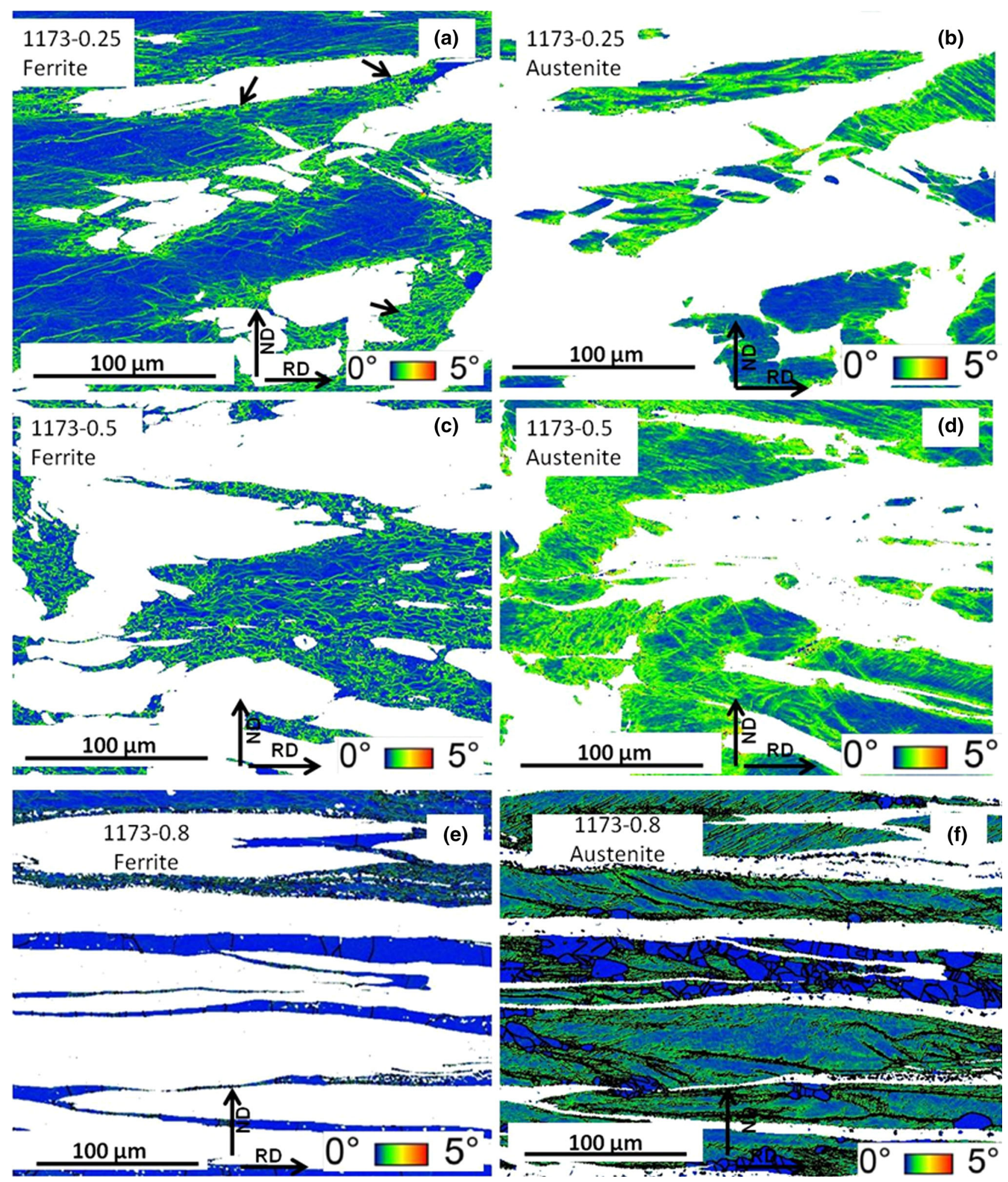

Fig. 11-LAM maps of $\delta$-ferrite and austenite regions of the samples hot deformed at $(a)$ through $(f) 1173 \mathrm{~K}\left(900{ }^{\circ} \mathrm{C}\right)$. The color legend showing the orientation gradient is given on each image (Color figure online).

grains, and as a result, cube texture continued to dominate even after the recrystallization. In the ferrite regions of the $1373-0.5$ or $1373-0.8$ sample, a few grains had slightly different texture, say, $\langle 011\rangle|| N D$ (i.e., Goss texture (Figures 7(c) and (e))). Formation of such texture can be associated with the grain growth process (mentioned earlier), possibly by a mechanism such as strain-induced boundary migration. ${ }^{[29]}$ Regarding the 


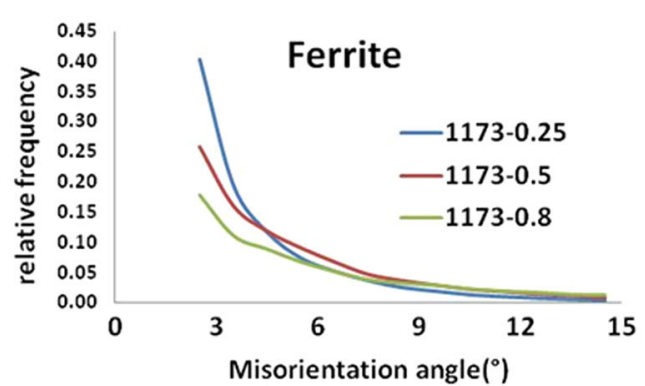

(a)

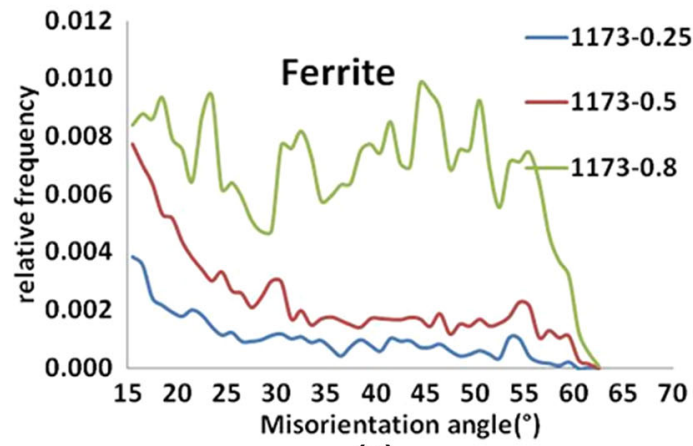

(c)

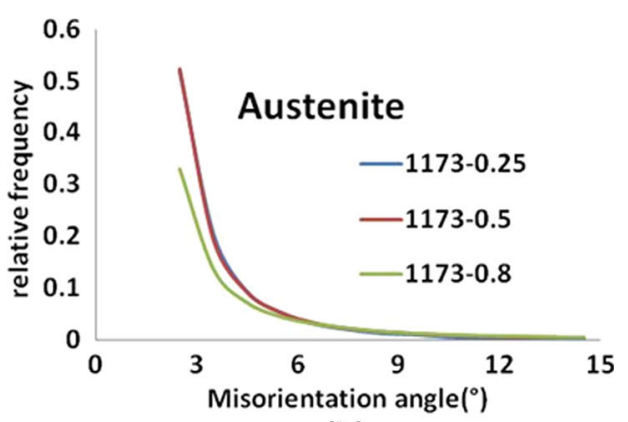

(b)

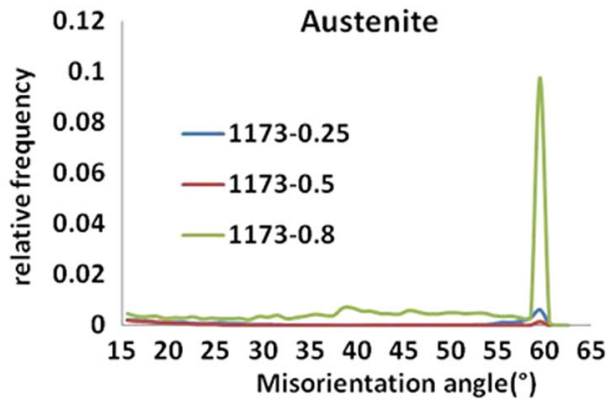

(d)

Fig. 12-Boundary misorientation distribution, as obtained from EBSD analysis, for $(a)$ and $(c) \delta$-ferrite and $(b)$ and $(d)$ austenite regions of the samples deformed at $1173 \mathrm{~K}\left(900^{\circ} \mathrm{C}\right)$ up to different strain levels.

texture in $\gamma$, an increase in strain from 0.25 to 0.5 increased the intensity of alpha-fcc fiber texture components, such as Brass texture $(\{011\}\langle 112\rangle)$ and rotated Goss texture $(\{011\}\langle 011\rangle)$, and decreased the intensity of cube, rotated-cube, and copper texture $(\{112\}\langle 111\rangle)$ (Figures 9(a) and (b)). The cube texture could have been present in the as-cast $\gamma$, and the copper texture possibly could have formed in the initial stage of deformation. As the strain increased to 0.8 , besides the presence of deformation texture components, a strong cube texture emerged inside $\gamma$ (Figure 9(c)). The cube texture is the ideal recrystallization texture of $\gamma$ and could have resulted from the DDRX of $\gamma^{\left[{ }^{[30]}\right.}$ Therefore, the evolution of microstructure and texture in $\delta$ and in $\gamma$, as a function of applied strain at $1373 \mathrm{~K}\left(1100{ }^{\circ} \mathrm{C}\right)$, confirms the dominance of DRV and CDRX in $\delta$-ferrite and DDRX in $\gamma$.

\section{Effect of Applied Strain on Hot-Flow Behavior at $1173 \mathrm{~K}\left(900^{\circ} \mathrm{C}\right)$ Deformation Temperature}

The phase maps of the samples deformed at $1173 \mathrm{~K}$ $\left(900{ }^{\circ} \mathrm{C}\right.$ ) up to strain levels of 0.25 and 0.50 are presented in Figure 10. LAM maps for $\delta$ and $\gamma$ regions of the $1173 \mathrm{~K}\left(900{ }^{\circ} \mathrm{C}\right)$ deformed samples are given in Figure 11. At the initial stage of deformation, softer ferrite phase deforms predominantly as compared to harder austenite, creating high strain concentration at the $\delta / \gamma$ interface (indicated by red arrows in Figure 10(a)), which can be confirmed from the LAM map of the 1173-0.25 sample, as indicated by black arrows in Figure 11(a). An increase in applied strain resulted in more uniform strain distribution inside $\delta$ (Figure 11(c)). As the rate of DRV in $\delta$ is comparatively slower at $1173 \mathrm{~K}\left(900{ }^{\circ} \mathrm{C}\right)$ than at $1373 \mathrm{~K}(1100$ $\left.{ }^{\circ} \mathrm{C}\right), \delta$ becomes strain hardened upon deformation at $1173 \mathrm{~K}\left(900^{\circ} \mathrm{C}\right)$, and as a result, $\gamma$ deforms to a greater extent. Both slipping and twinning mechanisms were possibly active during the deformation of $\gamma$ at $1173 \mathrm{~K}$ $\left(900{ }^{\circ} \mathrm{C}\right)$ (Figures 10(b) and 11(b) and (d)). Upon heavy deformation $(\varepsilon=0.8)$ at $1173 \mathrm{~K}\left(900{ }^{\circ} \mathrm{C}\right), \delta$ and $\gamma$ regions arrange in the form of alternate bands of elongated thin layers (Figure 3(d) and 11(e) and (f)). Some regions inside the heavily deformed $\delta$ and $\gamma$ layers also become strain-free recrystallized regions (Figures 11(e) and (f)).

The boundary misorientation distributions determined from the EBSD analysis are presented both in terms of relative scale (fraction) and absolute scale (number of boundaries per unit area, $\mathrm{mm}^{2}$ ) in Figures 12 and 13, respectively. The distributions clearly show the decrease in LAB fraction and corresponding rise in $\mathrm{HAB}$ fraction in $\delta$-ferrite, with the increase in applied strain. The HAB fraction particularly increased as the strain increased from 0.5 to 0.8 (Figures 12(c) and 13(c)) accompanied by an increase in recrystallized fraction (Table II). A small amount of recrystallization was even noticed in the 1173-0.5 sample, as indicated by white arrows in Figure 10(b). The boundary misorientation distributions of austenite regions were similar in the case of 1173-0.25 and 1173-0.5 samples (Figures 12(b) and (d) and 13(b) and (d)). As the applied strain increased to 0.8 , the fraction of $\mathrm{LAB}$ decreased and the same for $\mathrm{HAB}$ increased for all 


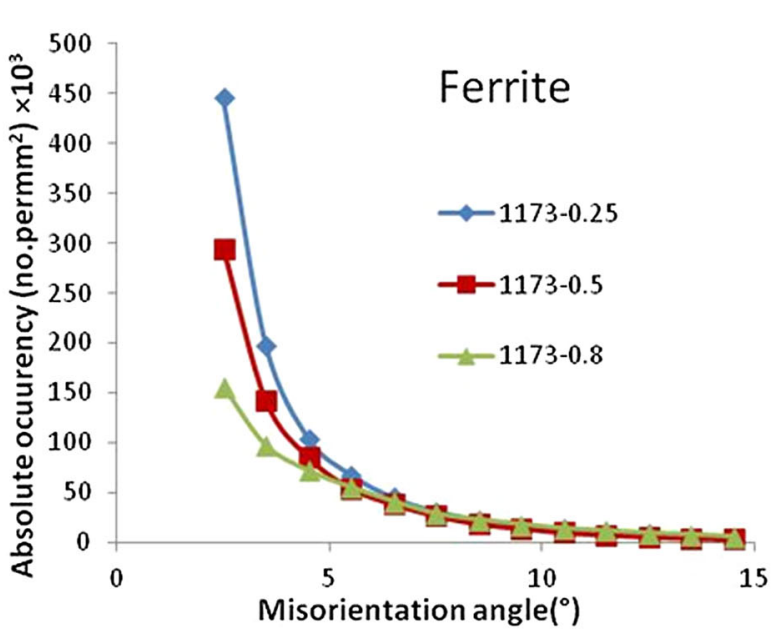

(a)

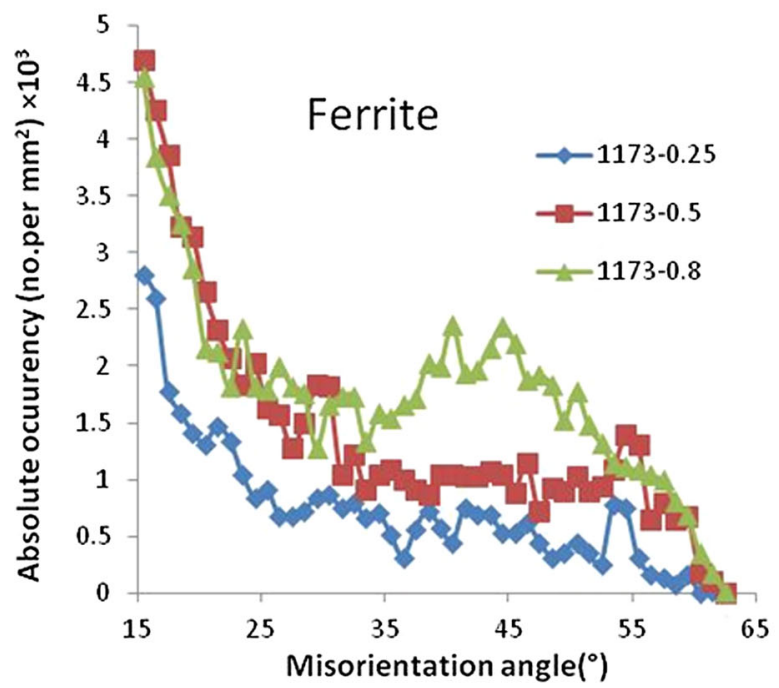

(c)

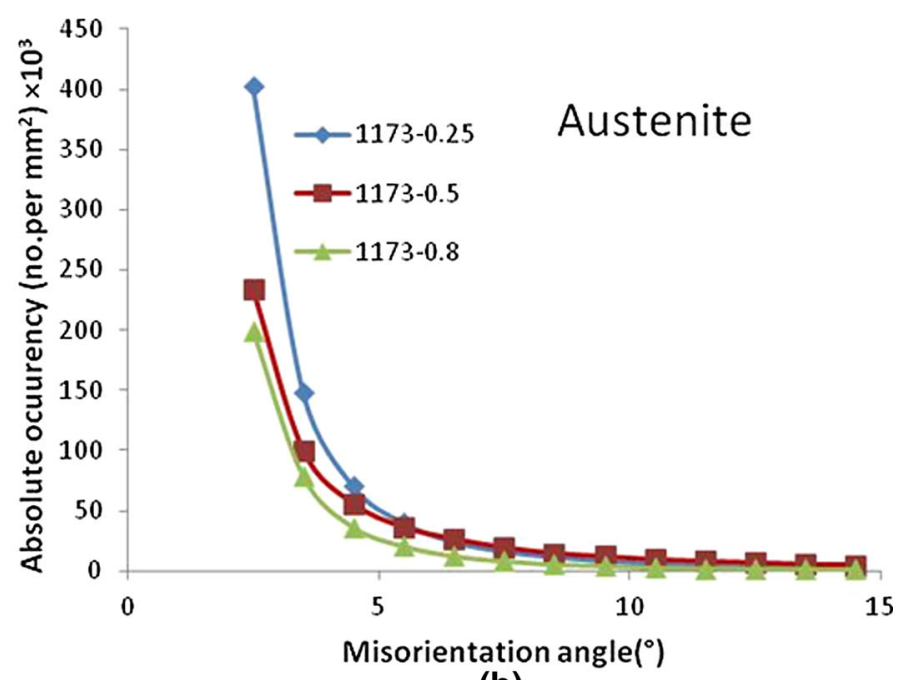

(b)

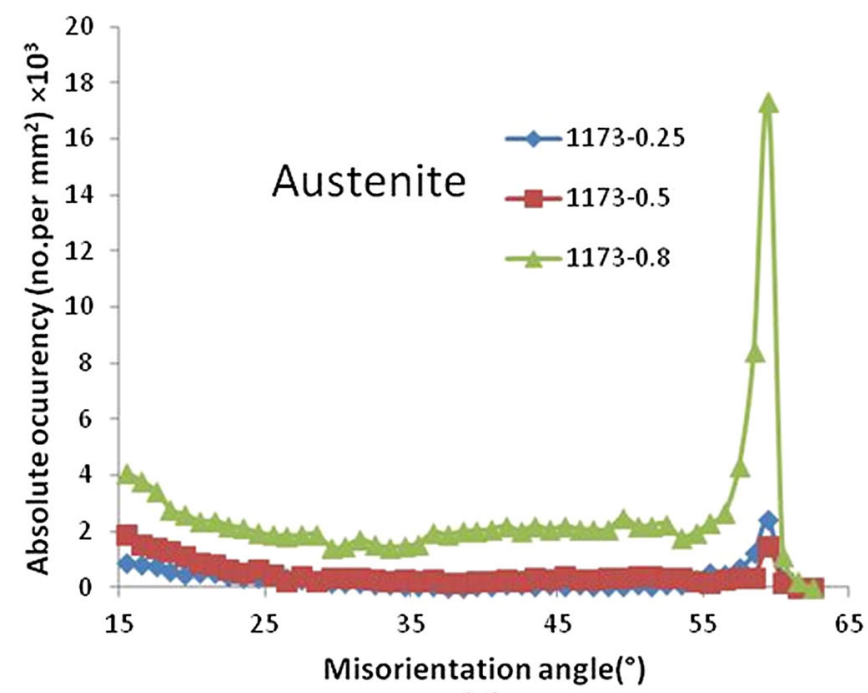

(d)

Fig. 13-Boundary misorientation distribution represented in absolute scale (number of boundaries per unit area, mm ${ }^{2}$ ), as obtained from the EBSD analysis, for $(a)$ and $(c) \delta$-ferrite and $(b)$ and $(d)$ austenite regions of the samples deformed at $1173 \mathrm{~K}\left(900{ }^{\circ} \mathrm{C}\right)$ up to different strain levels.

misorientation angles, particularly at 60-deg misorientation (Figures 12(b) and (d) and Figures 13(b) and (d)).

The IPF maps for $\delta$ and $\gamma$ regions of the samples deformed at $1173 \mathrm{~K}\left(900^{\circ} \mathrm{C}\right)$ are shown in Figure 14. As the cast and reheated structure was deformed, solidification and deformation texture dominated up to 0.5 strain (Figures 14(a) through (d)). As the strain increased to 0.8 , new strain-free grains formed both in $\delta$ and in $\gamma$; some of those grains tended to show random texture, while others retained deformation texture (Figures 14(e) and (f)). The ferrite texture represented in the $\Phi_{2}=45 \mathrm{deg}$ ODF section clearly showed the dominance of cube and rotated-cube textures at all strain levels (Figure 14). Gradual transformation from solidification to deformation texture is evident from the ODF sections of the 1173-0.25 and 1173-0.5 samples (Figures 15(a) and (b)). The intensity of texture, however, decreased in the 1173-0.8 sample (Figure 15(c)). The preceding discussion indicates that the deformation of $\delta$-ferrite and CDRX of some fraction of $\delta$ governed the ferrite texture in $900^{\circ} \mathrm{C}$ deformed samples. The formation of randomly oriented grains can be attributed to the grain growth, which is certainly less severe at lower $T_{\text {def }}$ (i.e., $\left.1173 \mathrm{~K}\left(900{ }^{\circ} \mathrm{C}\right)\right)$ than higher $T_{\text {def }}\left(1373 \mathrm{~K}\left(1100{ }^{\circ} \mathrm{C}\right)\right)$, as evident from the recrystallized $\delta$-grain size in Table II.

The crystallographic texture in $\gamma$ regions of $1173 \mathrm{~K}$ $\left(900{ }^{\circ} \mathrm{C}\right)$ deformed samples, presented in Figure 16, shows the dominance of deformation texture components such as Copper, Brass, Rotated Goss, and S. A small amount of cube texture also evolved in the $1173-0.8$ sample. The recrystallized fraction in $\gamma$ is smaller than that in $\delta$ for $T_{\text {def }}=1173 \mathrm{~K}\left(900{ }^{\circ} \mathrm{C}\right)$ (Table II). From the preceding evidence, it is difficult to conclusively state the exact recrystallization mechanism taking place in $\gamma$. The increases in HAB fraction in the boundary misorientation distribution in Figures 12(d) 


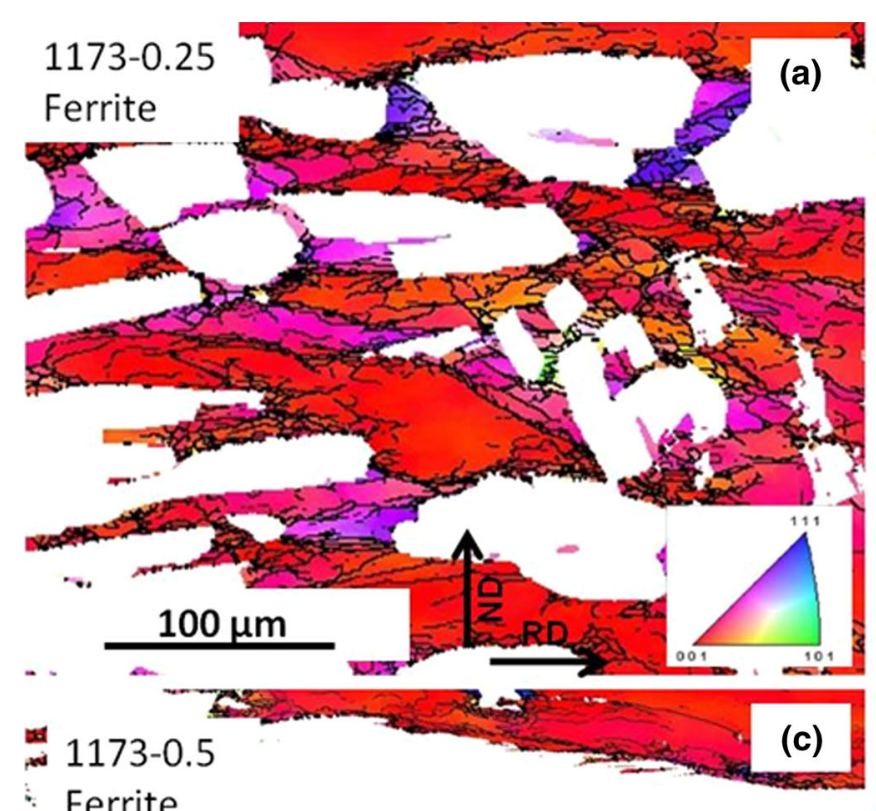

$1173-0.25 ; 0$ -

(b)
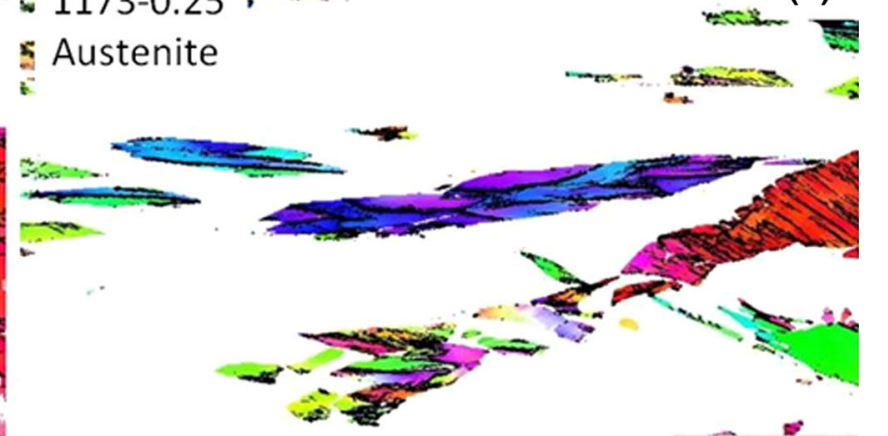

Ferrite
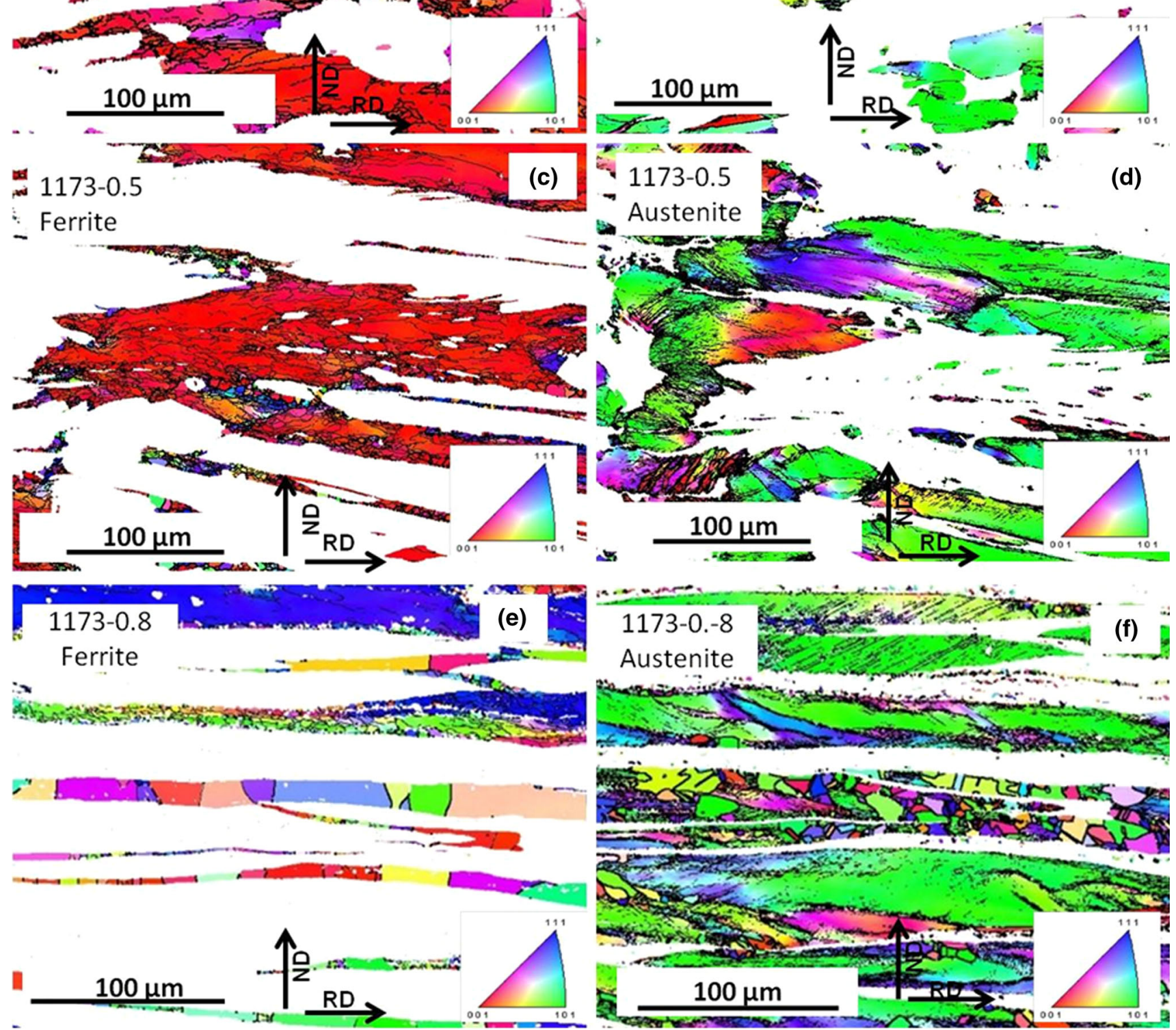

Fig. 14 -ND-IPF maps for $(a),(c)$, and $(e) \delta$-ferrite and $(b),(d)$, and $(f)$ austenite regions of the samples deformed at $1173 \mathrm{~K}\left(900{ }^{\circ} \mathrm{C}\right)$ up to different strain levels. The ND-IPF color legend is given on each image (Color figure online).

and 13(d) for all misorientation angles, and particularly at 60-deg misorientation, indicate that both CDRX and DDRX could have taken place inside $\gamma$ at $1173 \mathrm{~K}(900$ $\left.{ }^{\circ} \mathrm{C}\right)$. DDRX resulted in the formation of annealing twins
(60 deg with respect to $\langle 111\rangle$ ) and small intensity of cube texture. CDRX, on the other hand, developed some strain-free regions, surrounded by HABs, retaining the deformation texture of $\gamma$. The decrease in $T_{\text {def }}$ from 1373 


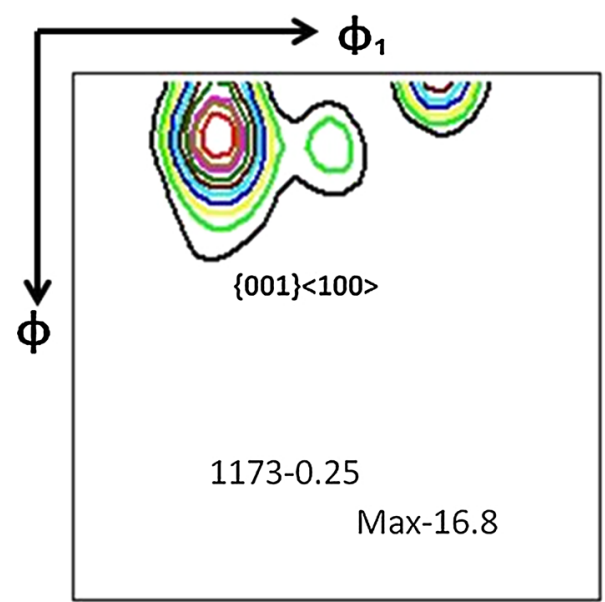

(a)

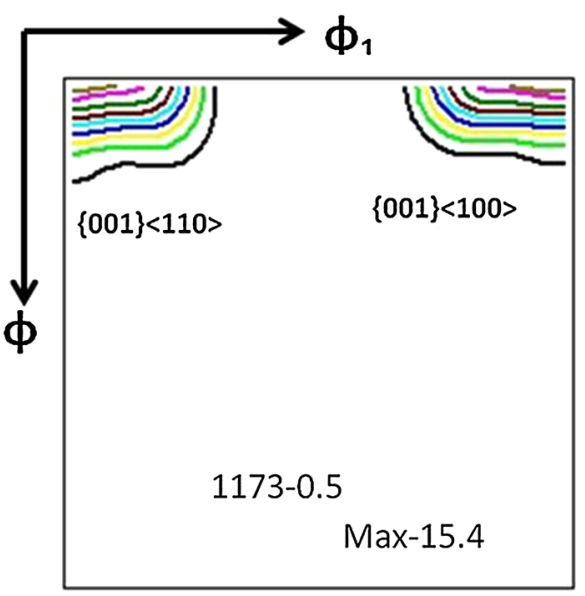

(b)

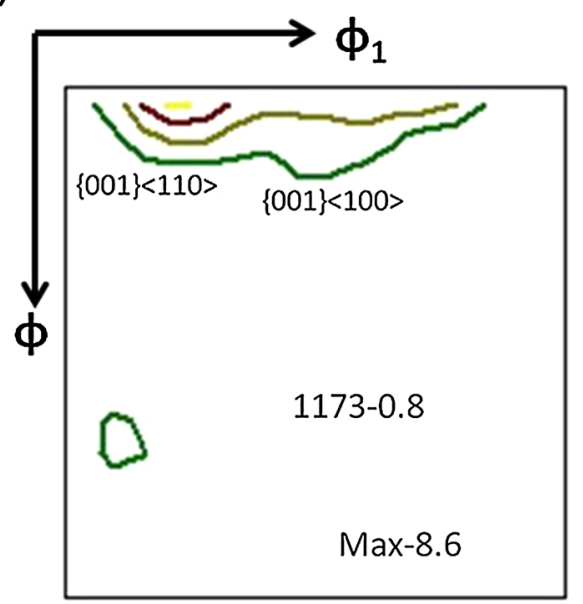

(c)

Fig. 15 - ODF presented on the $\Phi_{2}=45 \mathrm{deg}$ section of Euler's space for $\delta$-ferrite regions of the sample tested at $1173 \mathrm{~K}\left(900{ }^{\circ} \mathrm{C}\right)$ up to $(a) \varepsilon=$ $0.25,(b) \varepsilon=0.50$, and $(c) \varepsilon=0.80$.

$\mathrm{K}\left(1100{ }^{\circ} \mathrm{C}\right)$ to $1173 \mathrm{~K}\left(900{ }^{\circ} \mathrm{C}\right)$ reduced the thermal activation required for DDRX. On the other side, the decrease in severity of DRV of $\delta$ and the resultant strain hardening in $\delta$ increased the strain in $\gamma$, leading to CDRX of the same amount in $\gamma$.

\section{E. TEM Study on the Hot-Deformed Samples}

TEM images of the samples deformed at $1373 \mathrm{~K}$ $\left(1100{ }^{\circ} \mathrm{C}\right)$ at different applied strain levels are shown in Figure 17. Figure 17(a) shows the presence of dislocations (indicated by arrows) within the $\delta$-ferrite matrix at lower applied strain (0.25) in the 1373-0.25 sample. As the strain increased to 0.5 (in the 1373-0.5 sample), dislocation tangles and subgrain structure were observed (Figures 17(b) and (c)), which suggests that the microstructures were heavily recovered at intermediate strain level. The formation of grain boundaries and comparatively lower dislocation density within the $\delta$-ferrite matrix in Figures 17(d) and (e) indicate that CDRX could have taken place within $\delta$-ferritic grains at high strain level (0.8) in the 1373-0.8 sample. The dislocation pileup observed in Figure 17(f) near the interphase boundary in the 1173-0.8 sample confirms that plastic flow was restricted by the interphase boundaries at lower deformation temperatures.

\section{F. Effect of Hot Deformation Behavior on the Hardness of Compression-Tested Samples}

The average microhardness of ferrite and austenite regions for hot-deformed samples was presented in Figure 18 as the function of deformation temperature and applied strain. At deformation temperature $\left(T_{\text {def }}\right)$ of $1373 \mathrm{~K}\left(1100{ }^{\circ} \mathrm{C}\right)$, an increase in applied strain to $\varepsilon=$ 0.8 decreased the hardness of both $\delta$ and $\gamma$ regions (Figure 18(a)). This clearly indicates that dynamic softening mechanisms (DRV and DRX) were very active at $1373 \mathrm{~K}\left(1100{ }^{\circ} \mathrm{C}\right)$, especially upon heavy deformation $(\varepsilon \sim 0.8)$. Samples deformed at 1173 K (900 ${ }^{\circ} \mathrm{C}$ ) showed a completely different trend and the microhardness of $\delta$ and $\gamma$ regions, which increased with applied strain (Figure 18(b)). Therefore, in spite of DRV and DRX, strain hardening continued to dominate the $\delta$ and $\gamma$ regions, which increased the hardness. In general, as the deformation temperature decreased from $1373 \mathrm{~K}$ 


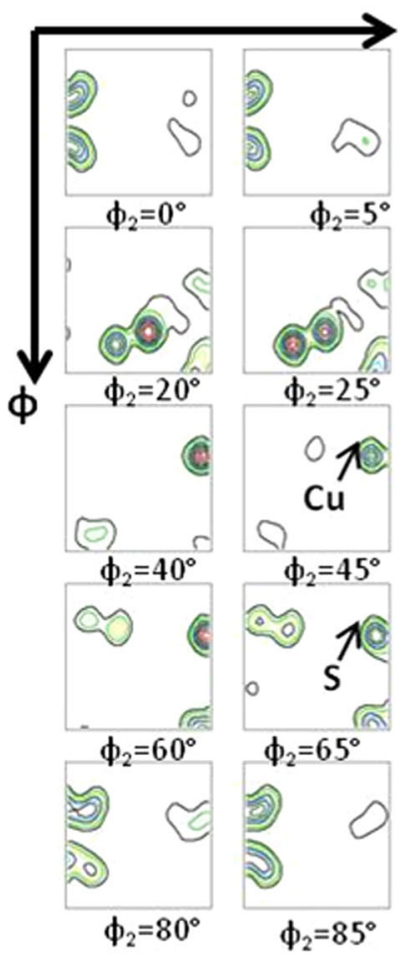

(a)

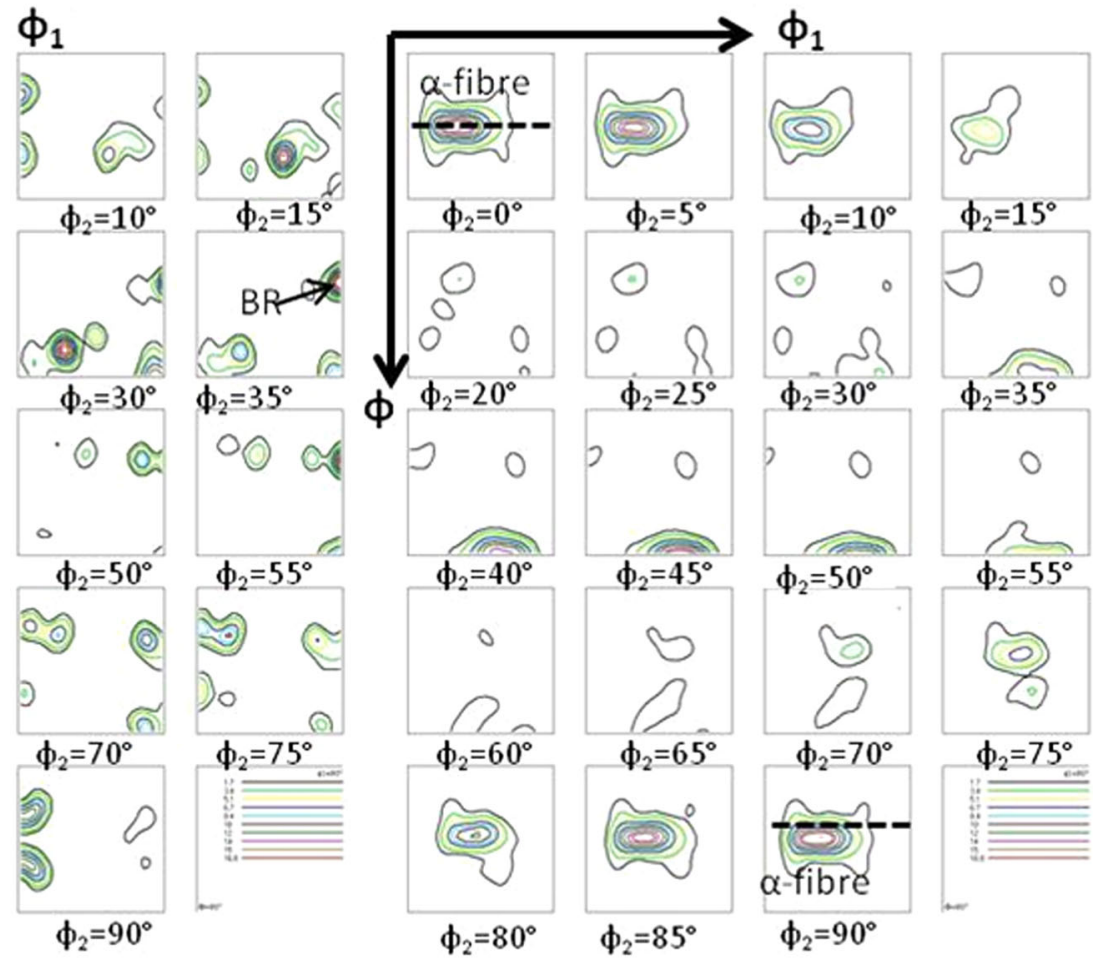

(b)

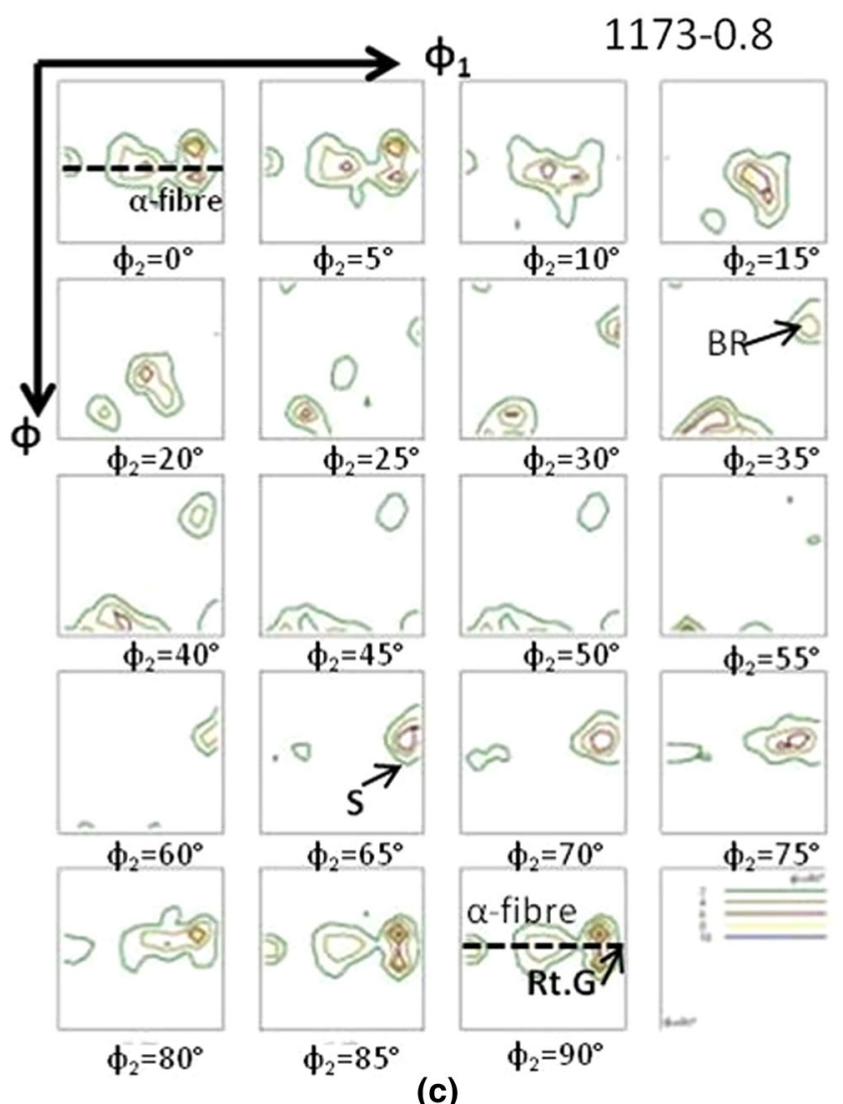

Fig. 16-ODF sections representing the texture in austenite $(\gamma)$ of the samples tested up to different strain levels $((a) \varepsilon=0.25,(b) \varepsilon=0.5$, and $(c) \varepsilon=0.8)$ at $1173 \mathrm{~K}\left(900{ }^{\circ} \mathrm{C}\right)$. The dominant texture components are mentioned on the images. Abbreviations: $\mathrm{Cu}=\mathrm{Copper}$ texture, Br $=$ Brass texture, Rt. Goss = Rotated Goss textures, $\mathrm{S}=\mathrm{S}$ texture, etc. 

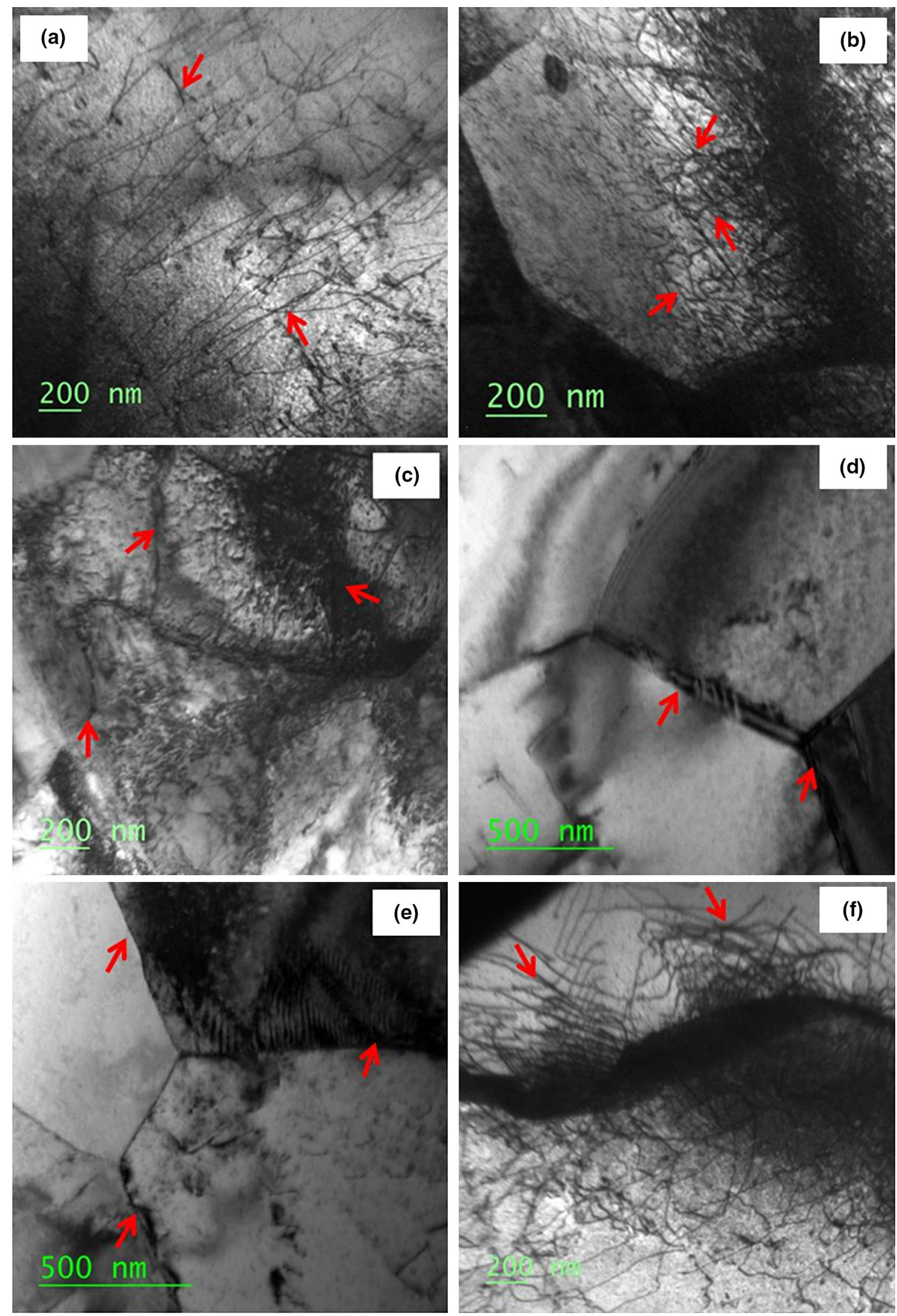

Fig. 17-TEM images of the hot-deformed samples showing $(a)$ dislocations in the 1373-0.25 sample, $(b)$ dislocation tangle in the $\delta$-ferrite matrix in the 1373-0.5 sample, $(c)$ subgrain formation in the1373-0.5 sample, $(d)$ and $(e)$ nearly strain-free recrystallized ferrite grains in the 1373-0.8 sample, and $(f)$ dislocation pileup at the interphase boundary in the 1173-0.8 sample. 


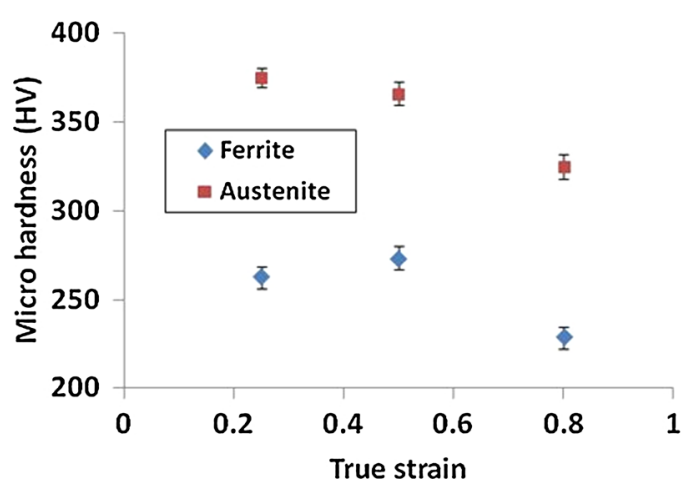

(a)

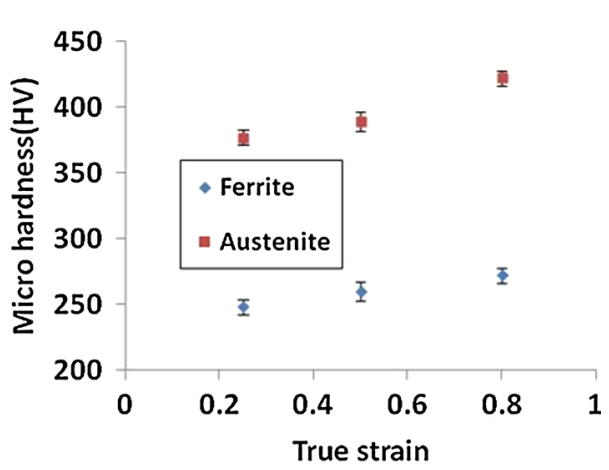

(b)

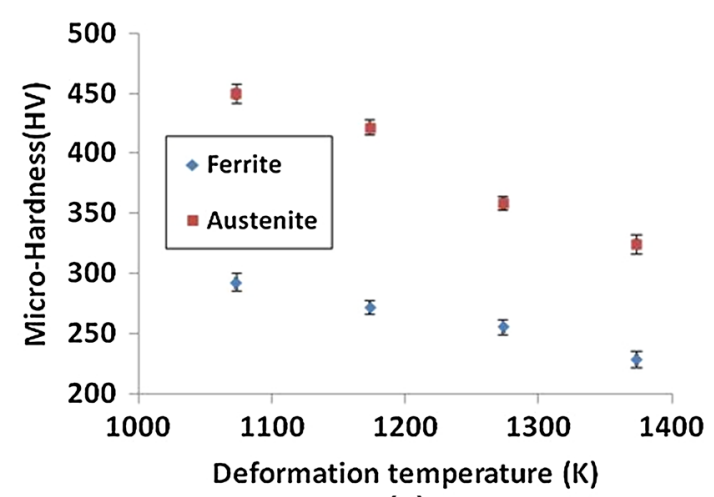

(c)

Fig. 18-Variation in average hardness of $\delta$-ferrite and austenite $(\gamma)$ as the function of true strain, for deformation at $(a) 1373 \mathrm{~K}\left(1100{ }^{\circ} \mathrm{C}\right)$ and (b) $1173 \mathrm{~K}\left(900^{\circ} \mathrm{C}\right)$ and $(c)$ as the function of deformation temperature for the strain of 0.80 .

$\left(1100{ }^{\circ} \mathrm{C}\right)$ to $1073 \mathrm{~K}\left(800{ }^{\circ} \mathrm{C}\right)$, the microhardness of $\delta$ and $\gamma$ regions for heavily deformed samples $(\varepsilon=0.8)$ increased continuously (Figure 18(c)). The $\Gamma$ continued to remain as the harder phase, and the difference in hardness between $\gamma$ and $\delta$ increased with the decrease in $T_{\text {def. }}$. Since $\gamma$ has lower SFE, the dislocation movement is more difficult in $\gamma$ than in $\delta,{ }^{[31-33]}$ as a result of which the dynamic restoration in $\gamma$ is more temperature sensitive than that in $\delta$.

\section{CONCLUSIONS}

The hot deformation behavior of 2101 grade lean DSS and the associated microstructural changes within individual phases $(\delta$-ferrite and austenite $(\gamma))$ were investigated by GLEEBLE testing over a range of deformation temperatures, $T_{\text {def }}\left(1073 \mathrm{~K}\right.$ to $1373 \mathrm{~K}\left(800{ }^{\circ} \mathrm{C}\right.$ to 1100 $\left.{ }^{\circ} \mathrm{C}\right)$ ), and true strains, $\varepsilon(0.25$ to 0.8$)$, at a constant strain rate $(1 / \mathrm{s})$. The major conclusions derived from the present study are as follows.

1. At $T_{\text {def }}$ in the range of $1273 \mathrm{~K}$ to $1373 \mathrm{~K}\left(1000^{\circ} \mathrm{C}\right.$ to $1100^{\circ} \mathrm{C}$ ), flow stress remained at a low level (80 to $110 \mathrm{MPa}$ ) and increased slightly with the increase in strain. As $T_{\text {def }}$ decreased to $1173 \mathrm{~K}\left(900{ }^{\circ} \mathrm{C}\right)$ and further to $1073 \mathrm{~K}\left(800{ }^{\circ} \mathrm{C}\right)$, the average flow stress level increased significantly 2 to 3 times (220 to 330 $\mathrm{MPa})$.
2. At $T_{\text {def }}=1373 \mathrm{~K}\left(1100{ }^{\circ} \mathrm{C}\right)$, an increase in strain from $\varepsilon=0.25$ to 0.80 significantly increased the dynamically recrystallized fraction in $\gamma$ up to 68 pct, and the DDRX is accompanied by the formation of annealing twins.

3. At $T_{\text {def }}=1173 \mathrm{~K}\left(900{ }^{\circ} \mathrm{C}\right)$, the dynamically recrystallized fraction in $\gamma$ was much higher $(\sim 14$ pct at $\varepsilon=0.8)$ than that of $T_{\text {def }}=1373 \mathrm{~K}(1100$ $\left.{ }^{\circ} \mathrm{C}\right)$. Both CDRX and DDRX contributed to that.

4. Both at $T_{\text {def }}=1373 \mathrm{~K}\left(1100{ }^{\circ} \mathrm{C}\right)$ and at $1173 \mathrm{~K}(900$ $\left.{ }^{\circ} \mathrm{C}\right)$, the DRX in $\delta$ was governed by CDRX. The recrystallized fraction decreased with the decrease in $T_{\text {def }}$ and the decrease in applied strain $(\sim 75 \mathrm{pct}$ at $1373 \mathrm{~K}\left(1100{ }^{\circ} \mathrm{C}\right)$ to $\sim 30$ pct at $1173 \mathrm{~K}\left(900{ }^{\circ} \mathrm{C}\right)$.

5. At a constant high strain level $(\varepsilon=0.8)$, the recrystallized fraction in $\gamma$ and $\delta$ decreased with the decrease in deformation temperature and became negligible at $T_{\text {def }}=1073 \mathrm{~K}\left(800{ }^{\circ} \mathrm{C}\right)$.

6. The texture in $\delta$-ferrite was predominantly cube and rotated cube at all deformation temperatures and applied strain levels investigated in the present study. At small applied strain (up to $\varepsilon=0.50$ ), the texture in $\gamma$ was dominated by deformation texture components such as Copper, Brass, Rotated Goss, and $\mathrm{S}$ components.

7. The TEM study shows that the increase in strain from 0.25 to 0.5 at $1373 \mathrm{~K}\left(1100{ }^{\circ} \mathrm{C}\right)$ resulted in subgrain formation by dislocation rearrangement and recovery of ferrite. Upon further increase in strain to 0.8 , pronounced recovery, i.e., CDRX in 
ferrite, led to the formation of recrystallized ferrite grains. At a lower deformation temperature of 1173 $\mathrm{K}\left(900{ }^{\circ} \mathrm{C}\right)$, dislocation pileup at the interphase boundaries indicates that those boundaries restricted the plastic flow. This observation explains the increasing hardness with the decrease in deformation temperature.

8. At a constant heavy deformation level $(\varepsilon=0.8)$, the average microhardness of $\delta$ and $\gamma$ regions increased continuously with the decrease in $T_{\text {def }}$. The rate of hardening with respect to the decrease in $T_{\text {def }}$ was higher in $\gamma$ than in $\delta$-ferrite.

9. The variation in average microhardness as the function of applied strain showed different trends for $T_{\mathrm{def}}=1373 \mathrm{~K}\left(1100{ }^{\circ} \mathrm{C}\right)$ and $T_{\text {def }}=1173 \mathrm{~K}$ $\left(900{ }^{\circ} \mathrm{C}\right)$. At $T_{\text {def }}=1373 \mathrm{~K}\left(1100{ }^{\circ} \mathrm{C}\right)$, an increase in applied strain decreased the hardness of $\delta$ and $\gamma$, due to the increase in microstructural softening by recrystallization. A $T_{\text {def }}=1173 \mathrm{~K}\left(900^{\circ} \mathrm{C}\right)$ increase in strain increased the hardness of $\delta$ and $\gamma$ regions, as the recrystallized fraction was lower than the deformed fraction.

\section{ACKNOWLEDGMENTS}

The authors acknowledge the experimental support received from Jindal Stainless Limited, the Indian Institute of Technology Kharagpur, and the Steel Authority of India. They also sincerely appreciate the financial support of the Department of Science and Technology, New Delhi, and the SGDRI Grant received from SRIC, IIT Kharagpur.

\section{NOMENCLATURE}

\section{ABBREVIATIONS}

CDRX Continuous dynamic recrystallization

DDRX Discontinuous dynamic recrystallization

DRV Dynamic recovery

DRX Dynamic recrystallization

DSS Duplex stainless steel

EBSD Electron backscatter diffraction

HAB High-angle boundary

IPF Inverse pole figure

LAB Low-angle boundary

LAM Local average misorientation

ODF Orientation distribution function

\section{SYMBOLS}

$T_{\text {def }} \quad$ Deformation temperature

$\varepsilon \quad$ Applied strain

$\dot{\varepsilon} \quad$ Strain rate $\gamma \quad$ Austenite

$\delta \quad$ Delta-ferrite

\section{REFERENCES}

1. Y.L. Fang, Z.Y. Liu, and G.D. Wang: J. Iron Steel Res. Int., 2011, vol. 18 , pp. $58-62$.

2. Y. Han, D. Zou, Z. Chen, G. Fan, and W. Zhang: Mater. Charact, 2011, vol. 62, pp. 198-203.

3. E. Evangelista, H.J. McQueen, M. Niewczas, and M. Cabibbo: Can. Metall. Q., 2004, vol. 43, pp. 339-54.

4. G.W. Fan, J. Liu, P.D. Han, and G.J. Qiao: Mater. Sci. Eng. A, 2009, vol. 515, pp. 108-12.

5. H. Farnoush, A. Momeni, K. Dehgani, J. AghaZadeh Mohandesi, and H. Keshmiri: Mater. Des., 2010, vol. 31, pp. 220-26.

6. A. Dehghan-Manshadi, M.R. Barnett, and P.D. Hodgson: Mater. Sci. Technol., 2007, vol. 23, pp. 1478-84.

7. A.M.J. Junior, G.S. Reis, and O. Balancin: Mater. Sci. Eng. A, 2011, vol. 528, pp. 1259-64.

8. S. Primig, K.S. Ragger, and B. Buchmeyr: Mater. Sci. Forum, 2014, vols. 783-86, pp. 973-79.

9. R.Z. Wang and T.C. Lei: Scripta Metall. Mater., 1994, vol. 31, pp. 1193-96.

10. C. Herrera, D. Ponge, and D. Raabe: Steel Res. Int., 2008, vol. 79, pp. 482-88.

11. C. Herrera, D. Ponge, and D. Raabe: Acta Mater., 2011, vol. 51, pp. 4653-64.

12. A. Iza-Mendia, A. Pin-Ol-Juez, J.J. Urcola, and I. Gutiérrez: Metall. Mater. Trans. A, 1998, vol. 29A, pp. 2975-86.

13. O. Balancin, W.A.M. Hoffmann, and J.J. Jonas: Metall. Mater. Trans. A, 2000, vol. 31A, pp. 1353-64.

14. A. Momeni and K. Dehghani: Mater. Sci. Eng. A, 2011, vol. 528, pp. $1448-54$.

15. A. Momeni, K. Dehghani, and X.X. Zhang: J. Mater. Sci., 2012, vol. 47, pp. 2966-74.

16. P. Cizek, B.P. Wyne, and W.M. Rainforth: J. Microsc., 2006, vol. 222, pp. $85-96$.

17. P. Cizek and B.P. Wyne: Mater. Sci. Eng. A, 1997, vol. 230, pp. 88-94.

18. Y.L. Fang, Z.Y. Liu, W. Xue, H.M. Song, and L.Z. Jiang: Iron Steel Inst. Jpn. Int., 2010, vol. 50, pp. 286-93.

19. Y. Liu, H. Yan, X. Wang, and M. Yan: Mater. Sci. Eng. A, 2013, vol. 575, pp. 41-47.

20. D.N. Zou, K. Wu, Y. Han, W. Zhang, B. Cheng, and G.J. Qiao: Mater. Design, 2013, vol. 51, pp. 975-82.

21. S. Patra, A. Ghosh, V. Kumar, D. Chakrabarti, and L.K. Singhal: Mater. Sci. Eng. A, 2016, vol. 660, pp. 61-70.

22. A. Ghosh, S. Patra, A. Chatterjee, and D. Chakrabarti: Metall. Mater. Trans. A, 2016, vol. 47A, pp. 2755-72.

23. J.J. Jonas, X. Quelennec, L. Jiang, and E. Martin: Acta Mater., 2009 , vol. 57 , pp. $2748-56$.

24. L. Duprez, B.C. De Cooman, and N. Akdut: Metall. Mater. Trans. A, 2002, vol. 34A, pp. 1931-38.

25. S. Kim and Y.C. Yoo: Met. Mater. Int., 2002, vol. 8, pp. 7-13.

26. S. Gourdet and F. Montheillet: Acta Mater., 2003, vol. 51, pp. 2685-99.

27. C. Herrera, D. Ponge, and D. Raabe: Proc. 3rd Int. Conf. on Thermo-Mechanical Processing of Steels, Padna, Italy, Sept. 10-12, 2008, http://edoc.mpg.de/377522.

28. N. Tsuji, K. Tsuzaki, and T. Maki: ISIJ Int., 1993, vol. 33, pp. 783-92.

29. N. Tsuji, K. Tsuzaki, and T. Maki: ISIJ Int., 1994, vol. 34, pp. 1008-17.

30. A. Paggi, G. Angella, and R. Donnini: Mater. Charact., 2015, vol. 107 , pp. 174-81.

31. R.K. Ray and J.J. Jonas: Int. Mater. Rev., 1990, vol. 35, pp. 1-36.

32. R.W. Hertzberg: Deformation and Fracture Mechanics of Engineering Materials, Wiley, New York, NY, 1995.

33. G.E. Dieter: Mechanical Metallurgy, McGraw-Hill, London, 1988. 